\title{
Bundle-specific associations between white matter microstructure and $A \beta$ and tau pathology at their connecting cortical endpoints in older adults at risk of Alzheimer's disease
}

\author{
Authors \\ Alexa Pichet Binette ${ }^{1,2}$, Guillaume Theaud ${ }^{3}$, François Rheault ${ }^{3}$, Maggie Roy ${ }^{3}$, D. Louis \\ Collins ${ }^{4}$, John C.S. Breitner ${ }^{1,2}$, Judes Poirier ${ }^{1,2}$, Maxime Descoteaux ${ }^{3}$, Sylvia \\ Villeneuve $^{1,2,4}$, for the PREVENT-AD Research Group

\section{Affiliations} \\ 1. Department of Psychiatry, Faculty of Medicine, McGill University, Montreal, Qc, H3A \\ 1Y2, Canada \\ 2. Douglas Mental Health University Institute, Montreal, Qc, H4H 1R3, Canada \\ 3. Sherbrooke Connectivity Imaging Laboratory (SCIL), Université de Sherbrooke, \\ Sherbrooke, Qc, J1K 2R1, Canada \\ 4. McConnell Brain Imaging Centre, Montreal Neurological Institute, Montreal, Qc, H3A \\ 2B4, Canada
}

\section{Corresponding Author}

Sylvia Villeneuve

Douglas Mental Health University Institute

Perry Pavilion Room E3417.1

6875 Boulevard LaSalle

Montreal, QC

Canada H4H 1R3

Phone: 514 761-6131 ext.: 3960

E-mail: Sylvia.villeneuve@mcgill.ca 


\begin{abstract}
Beta-amyloid $(\mathrm{A} \beta)$ and tau proteins, the pathological hallmarks of Alzheimer's disease (AD), are believed to spread through connected regions. Combining diffusion imaging and positron emission tomography, we investigated associations between $\mathrm{A} \beta$, tau and white matter microstructure specifically in bundles connecting brain regions in which AD pathology accumulates. In 126 cognitively normal elderly at risk of $\mathrm{AD}$, we focussed on free-water corrected diffusion measures in the cingulum, posterior cingulum, fornix and uncinate fasciculus. We found higher tissue fractional anisotropy and lower mean and radial diffusivity related to increased $A \beta$ at the cortical endpoints of the cingulum and fornix. We observed similar but stronger associations in the uncinate fasciculus, but with increased $A \beta$ and tau at the endpoints of this bundle. This consistent pattern of associations, with opposite directionality to the usual degeneration pattern in symptomatic individuals, suggests more restricted diffusion in bundles vulnerable to preclinical AD pathology.
\end{abstract}

Keywords: diffusion MRI, PET, amyloid, tau, uncinate fasciculus, cingulum, free-water, fornix 


\section{Introduction}

The progression of Alzheimer's disease (AD) neurodegeneration includes a long asymptomatic phase, during which accumulating pathology is accompanied by various brain changes (Jack et al., 2013; Sperling et al., 2011). Beta-amyloid (A $\beta$ ) and tau proteins, the pathological hallmarks of the disease (Duyckaerts et al., 2009), start to accumulate decades before signs of cognitive impairment (Bateman et al., 2012; Jansen et al., 2015). Positron emission tomography (PET) can image both proteins in vivo (Johnson et al., 2016; Klunk et al., 2004; Schöll et al., 2016), and thus help identifying the earliest brain changes associated with such pathologies. Both $\mathrm{A} \beta$ and tau accumulate in a distinct pattern of deposition that follows canonical brain networks/organization. A $\beta$ develops a widespread pattern of deposition that recapitulates a default mode network-like pattern, accumulating early in the frontal and parietal lobes (Mattsson et al., 2019; Villeneuve et al., 2015). Tau accumulates in a more localized pattern, starting in the medial temporal lobe in the preclinical phase of the disease, then spreading later to other parts of the temporal lobe and the rest of the brain in late stages (Braak and Braak, 1991). A prominent view is that pathology accumulates in functionally and/or structurally connected regions (Franzmeier et al., 2019; Seeley et al., 2009; Sepulcre et al., 2017; Vogel et al., 2020). Many studies have highlighted associations between AD pathology and brain functional activity early in the course of the disease (Berron et al., 2020; Jones et al., 2017; Mormino et al., 2011; Sepulcre et al., 2017). However, relations between pathology and white matter measures, as assessed by diffusion magnetic resonance imaging (MRI), remain elusive in preclinical AD. While white matter degeneration is clearly apparent in the late symptomatic stages, how white matter microstructure is 
affected early on in the disease process is less clear (Sachdev et al., 2013). Whole-brain diffusion MRI tractograms can represent the brain's white matter architecture, but these are difficult to reconstruct because of extensive crossing of whiter matter fibers and the complexity of tracking algorithms (Rheault et al., 2020). Recent advances in modeling and available algorithms have facilitated robust extraction of white matter bundles with automated methods, thereby allowing their more precise investigation. As well, more specific measures have become available for analysis of white matter (Dyrby et al., 2014). In particular, free-water corrected diffusion tensor measures may offer better estimates of white matter microstructure, yielding tissue-based fractional anisotropy and diffusivities after removing the free-water contribution to each voxel (Pasternak et al., 2009).

In 126 cognitively normal older adults at increased risk of AD, we investigated various diffusion-based measures of white matter microstructure in bundles that connect cortical regions vulnerable to $A \beta$ and tau deposition. As both of these pathologic proteins are thought to accumulate in connected regions, we hypothesized that diffusion measures in white matter bundles would first associate with the amount of pathology specifically in grey matter areas connected by such bundles rather than with more global measures of pathology. We sought to expand upon the few studies linking preclinical AD pathology and white matter microstructure and focussed on a priori bundles connecting brain regions targeted early by AD pathology, notably the cingulum bundle (Jacobs et al., 2018). The latter is a large association bundle under the cingulate gyri that connects anterior to posterior cingulate regions and curves further into the parahippocampal gyri of 
the temporal lobe. This bundle is typically affected in symptomatic AD dementia (Bubb et al., 2018; Jacobs et al., 2018; Kantarci et al., 2017; Roy et al., 2020; Wen et al., 2019) and given its location, could be preferentially affected by $\mathrm{A} \beta$, particularly in its anterior segment. Also of interest is the uncinate fasciculus, reported to be affected at the stage of mild cognitive impairment (Mito et al., 2018; Roy et al., 2020). This bundle connects parts of the limbic system, such as the hippocampus and amygdala in the temporal lobe, with the orbitofrontal cortex (Von Der Heide et al., 2013), brain regions thought to be key regions for tau and $\mathrm{A} \beta$ propagation respectively (van der Kant et al., 2020). Lastly, the fornix, which originates in the hippocampus, is another key bundle for investigation that could be affected by tau (Oishi and Lyketsos, 2014; Strain et al., 2018).

\section{Results}

\subsection{Approach and participants}

Using state-of-the-art methods in diffusion MRI modeling, tractography and tractometry, we aimed to better understand the associations between white matter microstructure of key bundles in preclinical $\mathrm{AD}$ and deposition of $\mathrm{A} \beta$ and tau at their endpoints. We reasoned that the preclinical stage of $\mathrm{AD}$ should be the ideal point at which to study these questions, given that this is a period during which AD pathology is spreading but overall brain structure and function remain largely preserved. We therefore studied a subset of 126 asymptomatic individuals at high risk of AD dementia from the PREVENT-AD cohort (Breitner et al., 2016). This cohort enrols cognitively normal older adults at risk of sporadic AD given their parental or multiple-sibling family history of the disease. At time of study, participants were on average 67.3 years of age, predominantly female and 
highly educated (Table 1). Based on a threshold established previously using global cortical A $\beta$ burden (McSweeney et al., 2020), we estimated that 20\% of the participants would be considered A $\beta$-positive. All underwent diffusion MRI an average of $1.1 \pm 0.8$ years prior to PET imaging (one completed MRI 5 years prior to PET, but results were unchanged when this participant was removed from analyses).

Table 1. Demographics

\begin{tabular}{ll}
\hline & PREVENT-AD participants $(\mathrm{n}=126)$ \\
\hline Age (years) & $67.3 \pm 4.8(68.6-83.2)$ \\
Sex F:M (\%F) & $94: 32(75 \%)$ \\
APOE4 carriers (\%) & $50(40 \%)$ \\
Education (years) & $15.2 \pm 3.3(7.0-24.0)$ \\
Global A $\boldsymbol{\beta}$ SUVR & $1.33 \pm 0.33(1.0-2.8)$ \\
Meta-ROI temporal tau SUVR & $1.18 \pm 0.12(0.87-2.0)$ \\
Mini-Mental State Examination & $28.8 \pm 1.2(24-30)$ \\
\hline
\end{tabular}

Values represent Mean \pm SD (Range). Participants with at least one $\varepsilon 4$ allele were considered APOE4 positive. The Mini-mental state evaluation was administered at the same time as PET.

A : beta-amyloid; APOE: apolipoprotein E; SUVR: standardized uptake value ratio

\subsection{Methodology overview}

We extracted free-water corrected diffusion tensor measures and fiber orientation distribution function (fODF)-based measures in bundles of interest. We reconstructed each individual's whole-brain tractogram using high angular resolution diffusion imaging and fODF, and employed automated tools to isolate the cingulum, the posterior cingulum, the uncinate fasciculus and the fornix (Garyfallidis et al., 2018; Rheault et al., 2018). Tractometry then generated bundle-specific quantification of six white matter properties (Cousineau et al., 2017; Rheault et al., 2017). These were tissue fractional anisotropy $\left(\mathrm{FA}_{\mathrm{T}}\right)$, mean diffusivity $\left(\mathrm{MD}_{\mathrm{T}}\right)$, axial diffusivity $\left(\mathrm{AD}_{\mathrm{T}}\right)$, and radial diffusivity $\left(\mathrm{RD}_{\mathrm{T}}\right)$. In each, ' $\mathrm{T}$ ' represents tissue in these free-water corrected diffusion tensor measures. We also report the free-water (FW) index, and fixel-based apparent fiber density (AFD). Free-water is thought to indicate a measure of neuroinflammation (Pasternak et al., 2009). AFD is thought to be more sensitive than FA and an indirect measure of axonal 
degeneration as it reflects the apparent number of axons (Raffelt et al., 2012). We calculated AFD specific to the fiber population within a single voxel, as per a fixel-based approach (Raffelt et al., 2015). To investigate the local relationships with AD pathology, we measured the $\mathrm{A} \beta$ and tau levels specifically at the cortical endpoints of each bundle. This approach allowed direct comparisons of the bundles of interest and associated pathology in their connected grey matter regions. An overview of the processing steps is shown in Figure 1. We further evaluated whether associations were independent of atrophy in connected cortical regions, and whether similar associations could be detected with typical diffusion tensor measures, i.e. FA, MD, AD, and RD (not corrected for freewater). Finally, we repeated the main analyses using a global measure of $A \beta$ and a temporal lobe measure of tau instead of testing for associations with AD pathology in grey matter areas connected by the respective white matter bundles. Our premise was that, if $\mathrm{AD}$ pathology propagates in connected regions, the associations between pathology and white matter measures should be evident specifically at the endpoints of these bundles. 


\section{Figure 1. Overview of the processing steps}

1
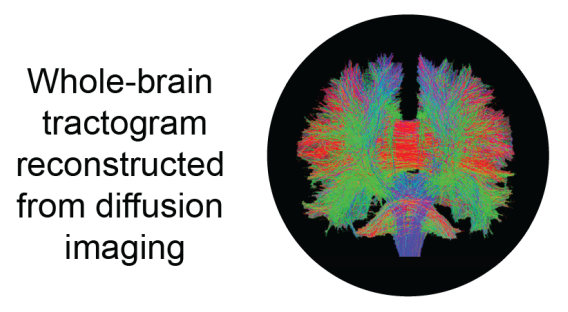

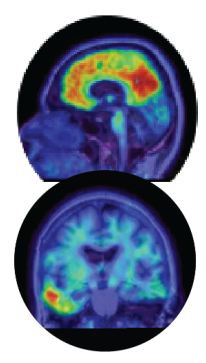

$A \beta$

tau

$$
\begin{gathered}
\text { Flortaucipir } \\
{\left[{ }^{18} \mathrm{~F}\right] \mathrm{AV} 1451}
\end{gathered}
$$

$\left[{ }^{18}\right.$ F]NAV4694

Register PET SUVR images to the native space diffusion MRI

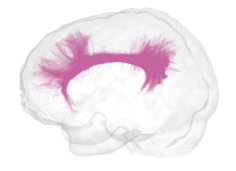

Cingulum

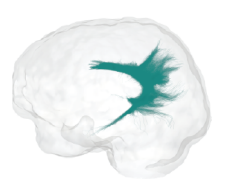

Posterior cingulum

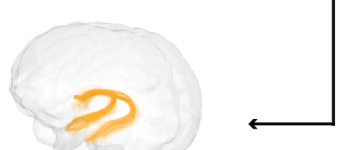

Fornix

\section{3} fasciculus Extract average diffusion measures for each bundle

Free-water corrected measures:

Tissue fractional anisotropy $\left(\mathrm{FA}_{T}\right)$

Tissue mean diffusivity $\left(M D_{T}\right)$

Tissue axial diffusivity $\left(A D_{T}\right)$

Tissue radial diffusivity $\left(\mathrm{RD}_{T}\right)$

Free-water index (FW)

Apparent fiber density (AFD)

\section{Extract SUVR at the cortical} endpoints of each bundle
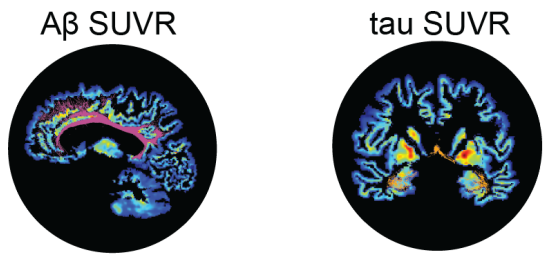

Example with the cingulum superimposed on $A \beta$ SUVR image and the fornix on tau

\section{4}
Bundle-specific assocations
Correlation between diffusion measures and $A \beta$ and tau SUVR at the cortical endpoints of each bundle
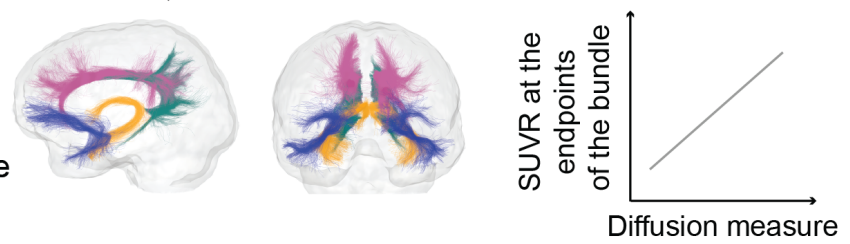

Whole-brain tractogram reconstructed using the TractoFlow Atlas-Based Segmentation pipeline and automated bundle extraction tools used to extract the four bundles of interest. Free-water corrected tensor measures and total apparent fiber density were calculated for each bundle. PET images were registered to the diffusion space in order to extract the A $\beta$ and tau SUVR directly at the cortical endpoints of each bundle.

A $\beta$ : beta-amyloid; PET: positron emission tomography; SUVR: standardized uptake value ratio

\subsection{Associations in the cingulum and the fornix restricted to $A \beta$}

Examining the amount of pathology at the cortical endpoints along the cingulum, and in

the temporal lobe with the fornix, we detected a similar pattern of association with white 
matter measures and $\mathrm{A} \beta$ in both bundles. More specifically, in the right anterior cingulum and right fornix, higher $\mathrm{FA}_{\mathrm{T}}$, lower $\mathrm{MD}_{\mathrm{T}}$, and lower $\mathrm{RD}_{\mathrm{T}}$ were related to higher A $\beta$ endpoint SUVR (Figure 2, Table 2 for the cingulum and Table 3 for the fornix). To evaluate whether such associations with $\mathrm{A} \beta$ were independent of tau pathology, we added tau SUVR at the corresponding endpoints as a covariate in these models. We found increased associations with endpoint $\mathrm{A} \beta$ in both bundles after adjusting for tau (Table 2 and 3). To evaluate whether association with $A \beta$ was also affected by atrophy in endpoint brain regions, we added grey matter volume of the following: anterior or posterior cingulate cortex in models with the cingulum; and hippocampal volume in models with the fornix. In both instances, associations increased with inclusion of terms for grey matter volume (Table 2 and 3). Note that for the cingulum, however, that this was true only with respect to volume of the anterior cingulate cortex. We found no associations between any white matter measures and tau in either the cingulum or the fornix (Supplementary Figure 1). Examining the same relations in the posterior cingulum, we found no associations between any diffusion measure and either $A \beta$ or tau in this bundle (Supplementary Figure 2). 
Figure 2. Associations between diffusion measures and $A \beta$ in the cingulum and temporal fornix
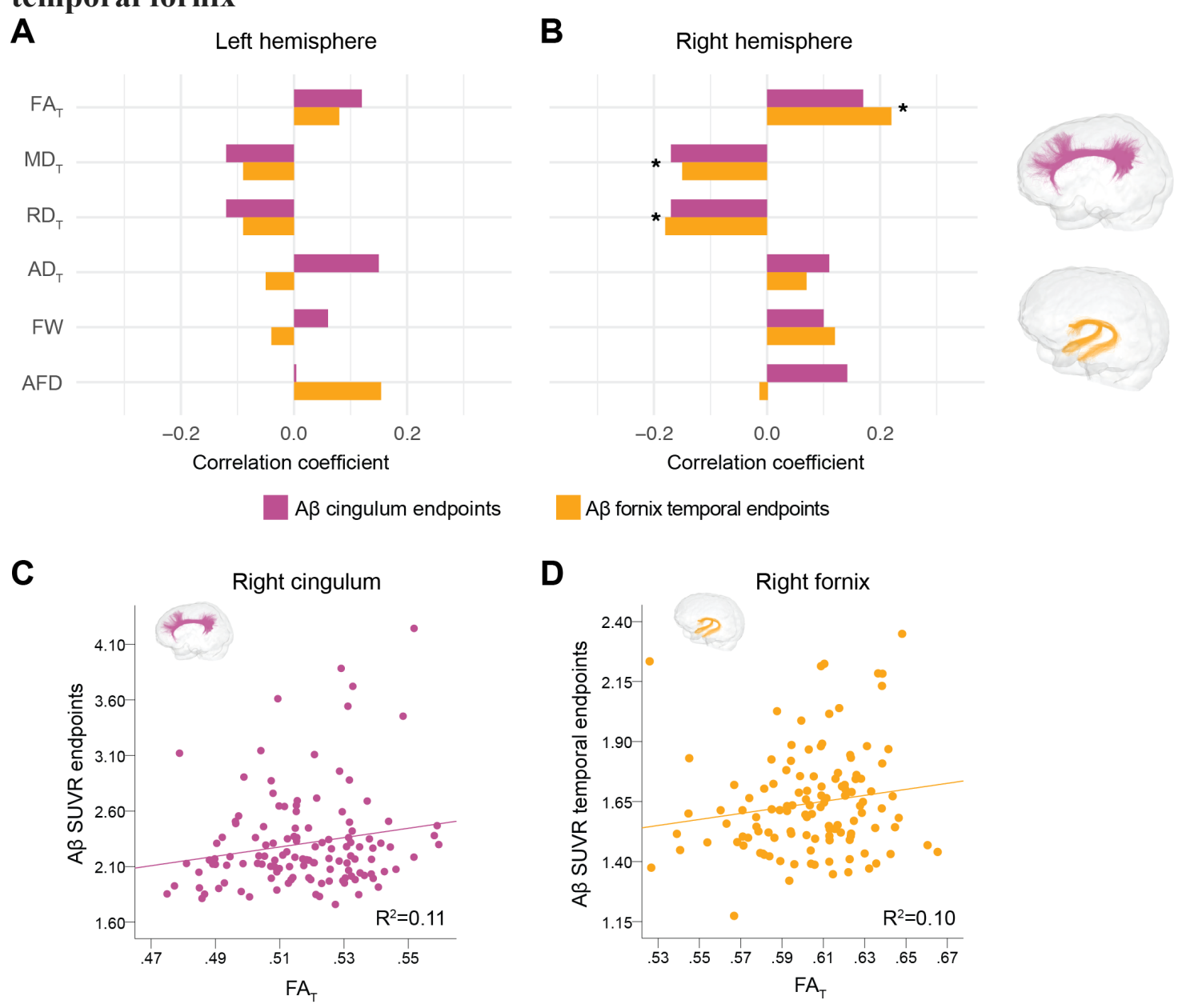

$\mathrm{R}_{\text {partial }}$ from regression models investigating associations between each diffusion measure (average diffusion measure in the bundle; independent variable) and A $\beta$ pathology at the cortical endpoints of the bundle in the left (A) and right (B) hemispheres. Magenta bars correspond to associations in the cingulum and orange bars, in the fornix. Models included age, sex, bundle volume (divided by total intracranial volume) as covariates.

* represents consistent associations at $\mathrm{p}<0.05$ for each bundle when further adjusting for either tau pathology or grey matter volume. Associations between $\mathrm{FA}_{\mathrm{T}}$ and $\mathrm{A} \beta$ in the right cingulum $(\mathrm{C})$ and right fornix (D)

$\mathrm{A} \beta$ : beta-amyloid; $\mathrm{FA}_{\mathrm{T}}$ : tissue fractional anisotropy; $\mathrm{MD}_{\mathrm{T}}$ : tissue mean diffusivity; $\mathrm{AD}_{\mathrm{T}}$ : tissue axial diffusivity; $\mathrm{RD}_{\mathrm{T}}$ : tissue radial diffusivity; $\mathrm{FW}$ : free-water index; $\mathrm{AFD}$ : fixel-based apparent fiber density 
Table 2. Associations between diffusion measures and pathology in the cingulum

\begin{tabular}{|c|c|c|c|c|c|c|c|c|c|c|c|c|}
\hline \multirow{2}{*}{\multicolumn{2}{|c|}{\begin{tabular}{l|l}
$n=126$ & \\
Associations with $\mathbf{A \beta}$
\end{tabular}}} & \multicolumn{5}{|c|}{ Left hemisphere } & \multicolumn{6}{|c|}{ Right hemisphere } \\
\hline & & \multirow[b]{2}{*}{$\mathbf{M D}_{\mathrm{T}}$} & \multirow{3}{*}{$\begin{array}{l}\mathbf{A D}_{\mathrm{T}} \\
0.15 \\
(0.11)\end{array}$} & \multirow{3}{*}{$\begin{array}{l}\mathbf{R D}_{\mathbf{T}} \\
-0.12 \\
(0.20)\end{array}$} & \multirow{3}{*}{$\begin{array}{l}\mathbf{F W} \\
0.06 \\
(0.55)\end{array}$} & \multirow{3}{*}{$\begin{array}{l}\text { AFD } \\
0.00 \\
(0.99)\end{array}$} & \multirow{3}{*}{\begin{tabular}{|l}
$\mathbf{F} \mathbf{A}_{\mathbf{T}}$ \\
0.17 \\
$(0.06)$ \\
$*, 1$ \\
\end{tabular}} & \multirow{3}{*}{$\begin{array}{l}\mathbf{M D}_{\mathrm{T}} \\
-0.17 \\
(0.06) \\
*, 1\end{array}$} & \multirow{3}{*}{$\begin{array}{l}\mathbf{A D}_{\mathbf{T}} \\
0.11 \\
(0.25)\end{array}$} & \multirow{3}{*}{$\begin{array}{l}\mathbf{R D}_{\mathbf{T}} \\
-0.17 \\
(0.06) \\
*, 1\end{array}$} & \multirow{3}{*}{$\begin{array}{l}\mathbf{F W} \\
0.10 \\
(0.30)\end{array}$} & \multirow{3}{*}{$\begin{array}{l}\text { AFD } \\
0.13 \\
(0.17)\end{array}$} \\
\hline & $\mathbf{F A}_{T}$ & & & & & & & & & & & \\
\hline $\begin{array}{l}\text { Cingulum } \\
\text { endpoints }\end{array}$ & $\begin{array}{l}0.12 \\
(0.20)\end{array}$ & $\begin{array}{l}-0.12 \\
(0.20)\end{array}$ & & & & & & & & & & \\
\hline \multicolumn{13}{|c|}{ Associations with tau } \\
\hline $\begin{array}{l}\text { Cingulum } \\
\text { endpoints }\end{array}$ & $\begin{array}{l}0.05 \\
(0.58) \\
\end{array}$ & $\begin{array}{l}-0.05 \\
(0.58) \\
\end{array}$ & $\begin{array}{l}0.08 \\
(0.36) \\
\end{array}$ & $\begin{array}{l}-0.05 \\
(0.57) \\
\end{array}$ & $\begin{array}{l}0.06 \\
(0.50)\end{array}$ & $\begin{array}{l}0.05 \\
(0.60) \\
\end{array}$ & $\begin{array}{l}-0.05 \\
(0.61) \\
\end{array}$ & $\begin{array}{l}0.05 \\
(0.61) \\
\end{array}$ & $\begin{array}{l}0.00 \\
(0.97)\end{array}$ & $\begin{array}{l}0.05 \\
(0.61) \\
\end{array}$ & $\begin{array}{l}0.00 \\
(0.98) \\
\end{array}$ & $\begin{array}{l}0.07 \\
(0.47)\end{array}$ \\
\hline \multicolumn{13}{|c|}{$\begin{array}{l}\mathrm{R}_{\text {partial }} \text { and ( } \mathrm{p} \text {-values) from regression models investigating associations between each diffusion } \\
\text { measure (average diffusion measure in the bundle; independent variable) and pathology at the } \\
\text { cortical endpoints along the cingulum (dependent variable). Models included age, sex, bundle } \\
\text { volume (divided by total intracranial volume) as covariates. } \\
* \text { becomes significant ( } \mathrm{p}=0.04 \text { ) when adding tau endpoints SUVR as a covariate } \\
{ }^{1} \text { becomes significant }(\mathrm{p}=0.02 \text { ) when adding anterior cingulate volume (divided by total } \\
\text { intracranial volume) as a covariate, but remains unchanged when adding posterior cingulate } \\
\text { volume as a covariate } \\
\left.{ }^{2} \text { becomes significant ( } \mathrm{p}=0.04\right) \text { when adding anterior cingulate volume as a covariate }\end{array}$} \\
\hline
\end{tabular}

Table 3. Associations between diffusion measures and pathology in the fornix

\begin{tabular}{|c|c|c|c|c|c|c|c|c|c|c|c|c|}
\hline \multicolumn{7}{|c|}{ Left hemisphere $(n=118)$} & \multicolumn{6}{|c|}{ Right hemisphere $(n=120)$} \\
\hline \multicolumn{7}{|c|}{ Associations with $\mathbf{A \beta}$} & & & & & & \\
\hline & $\mathbf{F A}_{\mathrm{T}}$ & $\mathbf{M D}_{\mathrm{T}}$ & $\mathbf{A D}_{\mathrm{T}}$ & $\mathbf{R D}_{\mathrm{T}}$ & FW & AFD & $\mathbf{F} \mathbf{A}_{T}$ & $\mathbf{M D}_{\mathrm{T}}$ & $\mathbf{A D}_{\mathrm{T}}$ & $\mathbf{R D}_{\mathrm{T}}$ & FW & AFD \\
\hline $\begin{array}{l}\text { Temporal } \\
\text { endpoints }\end{array}$ & $\begin{array}{l}0.08 \\
(0.38)\end{array}$ & $\begin{array}{l}-0.09 \\
(0.35)\end{array}$ & $\begin{array}{l}-0.05 \\
(0.62)\end{array}$ & $\begin{array}{l}-0.09 \\
(0.34)\end{array}$ & $\begin{array}{l}-0.04 \\
(0.67)\end{array}$ & $\begin{array}{l}0.15 \\
(0.13)\end{array}$ & $\begin{array}{l}0.22 \\
(0.02) \\
*, 1\end{array}$ & $\begin{array}{l}-0.15 \\
(0.11) \\
*, 1\end{array}$ & $\begin{array}{l}0.07 \\
(0.48)\end{array}$ & $\begin{array}{l}-0.18 \\
(0.06) \\
*, 1\end{array}$ & $\begin{array}{l}0.12 \\
(0.19)\end{array}$ & $\begin{array}{l}-0.01 \\
(0.92)\end{array}$ \\
\hline \multicolumn{13}{|c|}{ Associations with tau } \\
\hline $\begin{array}{l}\text { Temporal } \\
\text { endpoints }\end{array}$ & $\begin{array}{l}-0.15 \\
(0.12)\end{array}$ & $\begin{array}{l}0.16 \\
(0.09)\end{array}$ & $\begin{array}{l}0.08 \\
(0.38)\end{array}$ & $\begin{array}{l}0.16 \\
(0.09)\end{array}$ & $\begin{array}{l}-0.10 \\
(0.29)\end{array}$ & $\begin{array}{l}0.02 \\
(0.88)\end{array}$ & $\begin{array}{l}-0.10 \\
(0.27)\end{array}$ & $\begin{array}{l}0.05 \\
(0.61)\end{array}$ & $\begin{array}{l}-0.08 \\
(0.40)\end{array}$ & $\begin{array}{l}0.07 \\
(0.46)\end{array}$ & $\begin{array}{l}-0.01 \\
(0.88)\end{array}$ & $\begin{array}{l}-0.06 \\
(0.5)\end{array}$ \\
\hline
\end{tabular}

$\mathrm{R}_{\mathrm{partial}}$ and (p-values) from regression models investigating associations between each diffusion measure (average diffusion measure in the bundle; independent variable) and pathology at the temporal endpoints of the fornix (dependent variable). Models included age, sex, bundle volume (divided by total intracranial volume) as covariates.

* more variance was explained when adding tau endpoints SUVR as a covariate $(\mathrm{R}=0.27$, $\mathrm{p}=0.003$ for $\mathrm{FA}_{\mathrm{T}} ; \mathrm{R}=-0.18, \mathrm{p}=0.05$ for $\mathrm{MD}_{\mathrm{T}} ; \mathrm{R}=-0.22, \mathrm{p}=0.02$ for $\mathrm{RD}_{\mathrm{T}}$ )

${ }_{1}^{1}$ more variance was explained when adding hippocampal volume (divided by total intracranial volume) as a covariate $\left(\mathrm{R}=0.23, \mathrm{p}=0.01\right.$ for $\mathrm{FA}_{\mathrm{T}} ; \mathrm{R}=-0.18, \mathrm{p}=0.05$ for $\mathrm{MD}_{\mathrm{T}} ; \mathrm{R}=-0.21, \mathrm{p}=0.03$ for $\mathrm{RD}_{\mathrm{T}}$ )

$\mathrm{A} \beta$ : beta-amyloid; $\mathrm{FA}_{\mathrm{T}}$ : tissue fractional anisotropy; $\mathrm{MD}_{\mathrm{T}}$ : tissue mean diffusivity; $\mathrm{AD}_{\mathrm{T}}$ : tissue axial diffusivity; $\mathrm{RD}_{\mathrm{T}}$ : tissue radial diffusivity; FW: free-water index; AFD: fixel-based apparent fiber density 


\subsection{Associations in the uncinate fasciculus with $A \beta$ and tau}

Overall, a consistent pattern of associations between white matter microstructure and pathology was apparent across the uncinate fasciculus, anterior cingulum and fornix.

The strongest relations between AD pathology and diffusion measures were observed in the uncinate fasciculus. Associations with both $\mathrm{A} \beta$ and tau were detected bilaterally at both its endpoints, i.e. in the frontal and temporal lobes (Figure 3, Table 4). More specifically, as in the cingulum and the fornix, higher $\mathrm{FA}_{\mathrm{T}}$, lower $\mathrm{MD}_{\mathrm{T}}$, lower $\mathrm{RD}_{\mathrm{T}}$, and higher AFD related to higher $\mathrm{A} \beta$ (Figure $3 \mathrm{~A}$ to $\mathrm{C}$ ) and tau (Figure 3D to F) SUVR at bundle endpoints. Higher $\mathrm{AD}_{\mathrm{T}}$ also related to higher tau SUVR, and higher FW index related to higher tau endpoint SUVR for the right uncinate fasciculus only (Figure 3D). All associations with frontal tau endpoint SUVR survive correction for multiple comparisons (Table 4). To evaluate whether associations detected with $A \beta$ or tau pathology were independent, we added tau SUVR in corresponding endpoints as a covariate in models with $A \beta$ as the dependent variable, and vice versa. The original significant associations with $A \beta$ appeared slightly less impressive $(p=0.08)$ with insertion of the tau covariates (Supplementary Table 1). However, initial associations with tau remained after inserting covariates for $\mathrm{A} \beta$ at bundle endpoints (Supplementary Table 1). Lastly, we added grey matter volume from the medial orbitofrontal cortex and from the parahippocampal gyri as a covariate in models assessing frontal and temporal endpoint SUVRs, respectively (Table 4). Apparently, atrophy has little influence on associations between white matter microstructure and pathology in this bundle as all associations remained. 


\section{Figure 3. Associations between diffusion measures and pathology in the uncinate} fasciculus
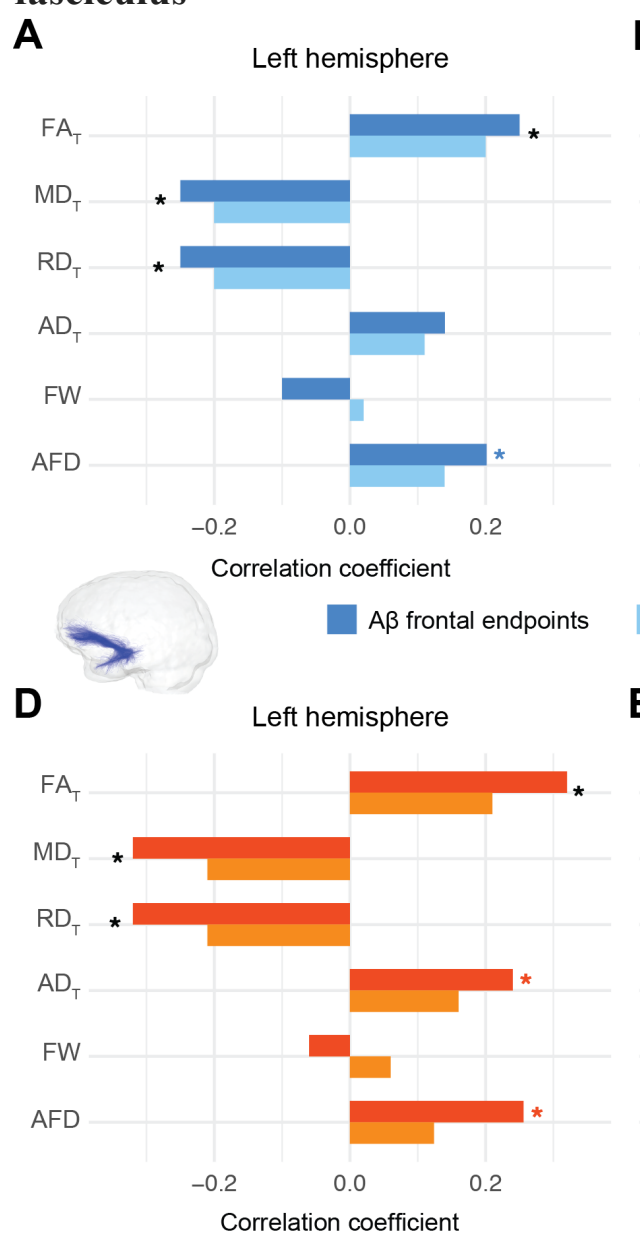

tau frontal endpoints

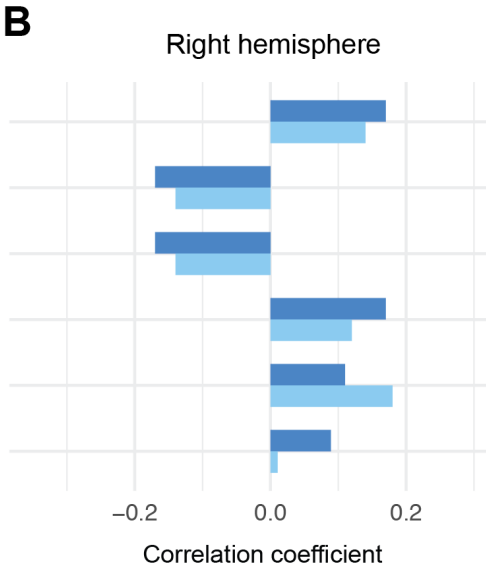

$A \beta$ temporal endpoints

E

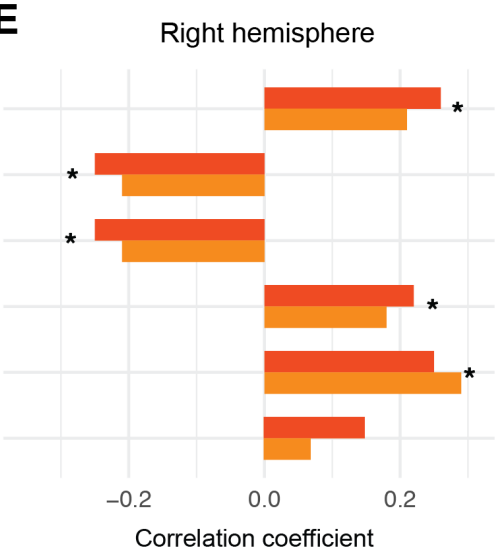

tau temporal endpoints
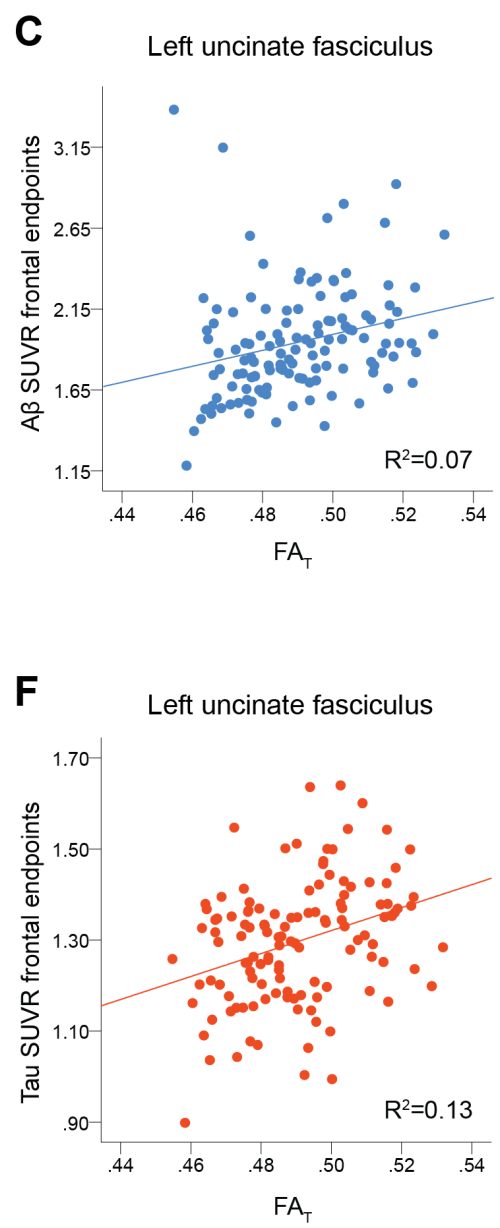

$\mathrm{R}_{\text {partial }}$ from regression models investigating associations between each diffusion measure (average diffusion measure in the bundle; independent variable) and $A \beta(A-B)$ or tau (D-E) pathology at the endpoints in the two ends of the uncinate fasciculus in the left and right hemispheres. Models included age, sex, bundle volume (divided by total intracranial volume) as covariates.

Representative associations between $\mathrm{FA}_{\mathrm{T}}$ with $\mathrm{A} \beta$ and tau are shown in $\mathrm{C}$ and $\mathrm{F}$.

* represents $\mathrm{p}<0.05$ and is black when associations at both endpoints were significant, and red when association at the frontal endpoints only was significant.

$\mathrm{A} \beta$ : beta-amyloid; $\mathrm{FA}_{\mathrm{T}}$ : tissue fractional anisotropy; $\mathrm{MD}_{\mathrm{T}}$ : tissue mean diffusivity; $\mathrm{AD}_{\mathrm{T}}$ : tissue axial diffusivity; $\mathrm{RD}_{\mathrm{T}}$ : tissue radial diffusivity; FW: free-water index; $\mathrm{AFD}$ : fixel-based apparent fiber density 
Table 4. Associations between diffusion measures and pathology in the uncinate fasciculus

\begin{tabular}{|c|c|c|c|c|c|c|c|c|c|c|c|c|}
\hline$n=126$ & \multicolumn{6}{|c|}{ Left hemisphere } & \multicolumn{6}{|c|}{ Right hemisphere } \\
\hline \multicolumn{13}{|c|}{ Associations with $\mathbf{A} \beta$} \\
\hline & $\mathbf{F A}_{\mathbf{T}}$ & $\mathbf{M D}_{\mathrm{T}}$ & $\mathbf{A D}_{\mathrm{T}}$ & $\mathbf{R D}_{\mathrm{T}}$ & FW & AFD & $\mathbf{F A}_{T}$ & $\mathbf{M D}_{\mathrm{T}}$ & $\mathbf{A D}_{\mathrm{T}}$ & $\mathbf{R D}_{\mathrm{T}}$ & FW & AFD \\
\hline $\begin{array}{l}\text { Frontal } \\
\text { endpoints }\end{array}$ & $\begin{array}{l}0.25 \\
(\mathbf{0 . 0 0 5} \\
)^{*}\end{array}$ & $\begin{array}{l}-0.25 \\
(\mathbf{0 . 0 0 5} \\
)^{*}\end{array}$ & $\begin{array}{l}0.14 \\
(0.12)\end{array}$ & $\begin{array}{l}-0.25 \\
(\mathbf{0 . 0 0 5} \\
)^{*}\end{array}$ & $\begin{array}{l}-0.10 \\
(0.28)\end{array}$ & $\begin{array}{l}0.20 \\
(0.026 \\
)^{*}\end{array}$ & $\begin{array}{l}0.17 \\
(0.06)^{+}\end{array}$ & $\begin{array}{l}-0.17 \\
(0.06)^{+}\end{array}$ & $\begin{array}{l}0.17 \\
(0.07)^{+}\end{array}$ & $\begin{array}{l}-0.17 \\
(0.06)^{+}\end{array}$ & $\begin{array}{l}0.11 \\
(0.21)\end{array}$ & $\begin{array}{l}0.08 \\
(0.37)\end{array}$ \\
\hline $\begin{array}{l}\text { Temporal } \\
\text { endpoints }\end{array}$ & $\begin{array}{l}0.20 \\
(0.03) \\
*\end{array}$ & $\begin{array}{l}-0.20 \\
(0.03) \\
*\end{array}$ & $\begin{array}{l}0.12 \\
(0.20)\end{array}$ & $\begin{array}{l}-0.20 \\
(0.03) \\
*\end{array}$ & $\begin{array}{l}0.02 \\
(0.84)\end{array}$ & $\begin{array}{l}0.13 \\
(0.15)\end{array}$ & $\begin{array}{l}0.14 \\
(0.14)\end{array}$ & $\begin{array}{l}-0.14 \\
(0.14)\end{array}$ & $\begin{array}{l}0.12 \\
(0.20)\end{array}$ & $\begin{array}{c}-0.14 \\
(0.14)\end{array}$ & $\begin{array}{l}0.18 \\
(0.05)\end{array}$ & $\begin{array}{l}0.01 \\
(0.88)\end{array}$ \\
\hline \multicolumn{13}{|c|}{ Associations with tau } \\
\hline $\begin{array}{l}\text { Frontal } \\
\text { endpoints }\end{array}$ & $\begin{array}{l}0.32 \\
(<\mathbf{0 . 0 0} \\
\mathbf{1})^{*}\end{array}$ & $\begin{array}{l}-0.32 \\
(<\mathbf{0 . 0 0} \\
\mathbf{1})^{*}\end{array}$ & $\begin{array}{l}0.24 \\
(\mathbf{0 . 0 1}) \\
*\end{array}$ & $\begin{array}{l}-0.32 \\
(<\mathbf{0 . 0 0} \\
\mathbf{0 1})^{*}\end{array}$ & $\begin{array}{l}-0.06 \\
(0.51)\end{array}$ & $\begin{array}{l}0.24 \\
(\mathbf{0 . 0 0 8} \\
)^{*}\end{array}$ & $\begin{array}{l}0.26 \\
(\mathbf{0 . 0 0 5} \\
)^{*} \\
\end{array}$ & $\begin{array}{l}-0.25 \\
(\mathbf{0 . 0 0 5} \\
)^{*}\end{array}$ & $\begin{array}{l}0.22 \\
(\mathbf{0 . 0 1}) \\
*\end{array}$ & $\begin{array}{l}-0.25 \\
(\mathbf{0 . 0 0 5} \\
)^{*} \\
\end{array}$ & $\begin{array}{l}0.25 \\
(\mathbf{0 . 0 0 6} \\
)^{*}\end{array}$ & $\begin{array}{l}0.15 \\
(0.10)\end{array}$ \\
\hline $\begin{array}{l}\text { Temporal } \\
\text { endpoints }\end{array}$ & $\begin{array}{l}0.21 \\
(0.02) \\
*\end{array}$ & $\begin{array}{l}-0.21 \\
(0.02) \\
*\end{array}$ & $\begin{array}{l}0.16 \\
(0.08)\end{array}$ & $\begin{array}{l}0.21 \\
(0.02) \\
*\end{array}$ & $\begin{array}{l}0.06 \\
(0.54)\end{array}$ & $\begin{array}{l}0.11 \\
(0.24)\end{array}$ & $\begin{array}{l}0.21 \\
(0.02) \\
*\end{array}$ & $\begin{array}{l}-0.21 \\
(0.02) \\
*\end{array}$ & $\begin{array}{l}0.18 \\
(0.05) \\
*\end{array}$ & $\begin{array}{l}-0.21 \\
(0.02) \\
*\end{array}$ & $\begin{array}{l}0.29 \\
(0.001 \\
)^{*}\end{array}$ & $\begin{array}{l}0.06 \\
(0.54)\end{array}$ \\
\hline
\end{tabular}

$\mathrm{R}_{\text {partial }}$ and (p-values) from regression models investigating associations between each diffusion measure (average diffusion measure in the bundle; independent variable) and pathology at the cortical endpoints of the two ends of the uncinate fasciculus (dependent variable). Models included age, sex, bundle volume (divided by total intracranial volume) as covariates. Bolded associations survived FDR correction at $\mathrm{q}=0.05$.

* association remains unchanged when grey matter volumes (divided by total intracranial volume) at the endpoint of the bundles were added as covariates in the respective models. + association becomes significant $(\mathrm{p}=0.05)$ when adding medial orbitofrontal cortex volume as a covariate

$\mathrm{A} \beta$ : beta-amyloid; $\mathrm{FA}_{\mathrm{T}}$ : tissue fractional anisotropy; $\mathrm{MD}_{\mathrm{T}}$ : tissue mean diffusivity; $\mathrm{AD}_{\mathrm{T}}$ : tissue axial diffusivity; $\mathrm{RD}_{\mathrm{T}}$ : tissue radial diffusivity; FW: free-water index; AFD: fixel-based apparent fiber density

\subsection{Importance of advanced free-water measures to these results}

To evaluate the sensitivity of free-water corrected measures over the typical tensor measures, we tested whether similar associations with pathology exist with FA, MD, AD and RD (i.e. not corrected for free-water). We failed to observe most of the abovedescribed associations when using these classical diffusion tensor measures. Specifically, no associations were found between $\mathrm{A} \beta$ or tau and any of the diffusion tensor measures in the cingulum or posterior cingulum. In the fornix, there was one isolated relationship between FA and the left temporal $A \beta$ endpoints $\left(R_{\text {partial }}=0.24 ; p=0.01\right)$. In the uncinate 
fasciculus, only a few associations were detected, the main ones being higher FA and AD related to higher tau pathology (Supplementary Table 2). The directionality of the associations was the same as for the free-water corrected measures.

\subsection{No associations with global measures of $A \beta$ or tau pathology}

Lastly, we found almost no associations between either $\mathrm{A} \beta$ or tau global scores and the diffusion measures in any of the bundles using either free-water corrected or classical tensor measures. The sole exception was one isolated association of higher FW index in the right uncinate fasciculus and higher tau SUVR, with $R_{\text {partial }}=0.23(p=0.01)$.

\section{Discussion}

The notion that $\mathrm{AD}$ pathology spreads through connected regions in the brain has foundations in rodent models (Ahmed et al., 2014; Palop and Mucke, 2010), although it is gaining credence in human neuroimaging studies. The spatial overlap between key regions of $\mathrm{A} \beta$ accumulation and connectivity hubs is striking (Buckner et al., 2005; Sepulcre et al., 2016). Tau has been found to propagate in connected regions independently of distance between them (Franzmeier et al., 2020; Vogel et al., 2020). Bundle-specific white matter neurodegeneration has also been associated with increased tau accumulation (Jacobs et al., 2018). Combining A $\beta$ - and tau-PET with recent advanced diffusion imaging analyses, we investigated AD pathology and white matter microstructure in a priori selected bundles that connect the brain regions where pathology accumulates. Our aim here was not to test the spreading hypothesis per se but, assuming that this hypothesis is correct, to focus on local effects of white matter bundle microstructure and pathology to 
increase probabilities of capturing early alterations. To do so, we investigated microstructure - pathological associations in a cohort of asymptomatic older adults younger than most typical aging or AD cohorts and enriched for preclinical AD due to their family history of the disease. We characterized the association focussing at a macrolevel on key bundles of interest, and at a micro-level on diffusion measures in these bundles and their associations with $\mathrm{A} \beta$ and tau levels specifically at their cortical endpoints. We found a consistent pattern of more restricted diffusion across the cingulum, the fornix, and the uncinate fasciculus, with higher $\mathrm{FA}_{\mathrm{T}}$, lower $\mathrm{MD}_{\mathrm{T}}$, and lower $\mathrm{RD}_{\mathrm{T}}$ being related to greater endpoint pathology. For the cingulum and fornix such associations were restricted to $A \beta$, but they were found both with $A \beta$ and tau in the uncinate fasciculus.

There are two important take-homes related to the main results. First, the pattern of association between pathology and microstructure was only detected using local $A \beta$ and tau at the bundle endpoints and not when using global AD burden scores. This finding suggests topographical relationships between pathology and white matter microstructural alterations in the early stage of AD. This "bundle-specific" approach through tractography and tractometry complements the typical approach of voxel-wise analyses (Harrison et al., 2020; Zhang et al., 2019) and yielded specific associations between white matter and pathology. Similarly, using more precise tissue measures with free-water corrected as opposed to classical diffusion tensor measures was critical to our findings, further highlighting the relevance of novel methods. Second, the directionality of the observed pattern of association opposes the classical pattern of degeneration. The classical degeneration pattern accompanying disease progression is characterized by lower 
anisotropy and higher diffusivity, representing loss of coherence in the white matter microstructure with AD progression (Caso et al., 2016; Sexton et al., 2011). This pattern of white matter degeneration develops invariably along the AD spectrum (Amlien and Fjell, 2014; Pereira et al., 2019), with associations often becoming detectable only in the mild cognitive impairment and dementia stages (Mito et al., 2018; Song et al., 2018; Wang et al., 2019; Wen et al., 2019), and very few in A $\beta$-positive cognitively normal participants (Rieckmann et al., 2016; Vipin et al., 2019). However, our consistent pattern of more restricted diffusion (higher FA and lower MD) being associated with more pathology in three bundles suggests that microstructural alterations captured with diffusion MRI might differ in the preclinical vs. the symptomatic phase of $\mathrm{AD}$, during which severe and irreversible atrophy has occurred. Supporting this biphasic relationship, in the Alzheimer Disease Neuroimaging Initiative dataset, FA increased from the A $\beta$ negative participants to those with intermediate $A \beta$ levels and decreased in those with high A $\beta$ (Dong et al., 2020). In another cohort of older adults with intact cognition and a family history of $\mathrm{AD}$, those with high levels of $\mathrm{A} \beta$ also had higher FA and lower MD compared to the $\mathrm{A} \beta$-negative participants, notably in the cingulum and the fornix (Racine et al., 2014). This possible biphasic relationship (Fortea et al., 2010; Montal et al., 2018) has important implication as it might obscure some association in the early disease stages.

Although more restricted diffusion with the presence of pathology was unanticipated, different biological mechanisms might underlie this phenomenon. For example, a loss of crossing fibers occurring as pathology accumulates could account for increased $\mathrm{FA}_{\mathrm{T}}$ in the early disease stage (Mito et al., 2018). Further, higher anisotropy and lower 
diffusivity might be due to hypertrophy, glial activation, neuronal or glial swelling in the asymptomatic phase (Fortea et al., 2010; Montal et al., 2018). Extracellular A $\beta$ plaques typically accumulate in the grey matter but have often been associated with gliosis (Spires-Jones and Hyman, 2014), which could restrict diffusion in the microstructural environment, as reported here with higher $\mathrm{FA}_{\mathrm{T}}$ and lower $\mathrm{MD}_{\mathrm{T}}$ and $\mathrm{RD}_{\mathrm{T}}$. Tau, on the other hand, is a microtubule-associated protein that stabilizes the axons. With disease progression, tau becomes hyperphosphorylated and detaches from the microtubules (Higuchi et al., 2002; Iqbal et al., 2009). We can hypothesize that the increasing presence of hyperphosphorylated tau along axons early on in AD pathological processes could restrict the diffusion, even more so when looking at tissue measures specifically.

We were surprised to find no associations between AD pathology and diffusion measures in the posterior cingulum, as this is a key bundle in AD (Agosta et al., 2011; Caso et al., 2016; Zhuang et al., 2012). This bundle is certainly altered in the symptomatic stage, but it is possible that the microstructure of the posterior part of the cingulum is not affected early by pathology. Alternatively, this region might have already entered a shift toward the classical degeneration pattern (lower $\mathrm{FA}_{\mathrm{T}}$ and $\mathrm{AFD}$, higher $\mathrm{MD}_{\mathrm{T}}$ and $\mathrm{RD}_{\mathrm{T}}$ ) that would be related to higher AD pathology in some individuals. This opposite direction of associations that switches with disease severity would make linear findings impossible to detect in individuals that are slowly progressing from cognitively normal to cognitively impaired. On the other hand, the strongest and more numerous associations were detected in the uncinate fasciculus. This bundle has an interesting anatomy, connecting regions at the intersection of both $\mathrm{A} \beta$ (frontal lobe) and tau (temporal lobe) deposition patterns. We 
speculate that the particular localization of the uncinate fasciculus with regards to $A \beta$ and tau deposition might confer early vulnerability to pathological insults. Its possible vulnerability might also be increased due to retrogenesis. This concept postulates that late-myelinated fibers, from temporal and neocortical regions, are affected first in the disease course, whereas thicker fibers myelinated earlier in development are more resistant to neurodegeneration/disease (Alves et al., 2015; Bartzokis, 2004, 2011). For instance, the orbitofrontal cortex is not only a region where $\mathrm{A} \beta$ pathology accumulates early but is also a highly plastic late-developing region, typically affected in aging (Fjell et al., 2014; Pichet Binette et al., 2020).

The direct investigation of pathology at the cortical endpoints of white matter fiber bundles and microstructure in such bundles was possible due to recent advances in diffusion imaging modeling, tractography, bundle extraction and tractometry quantification. However, there are several limitations to these techniques and to our study. First, there are no common standards (yet) to extract pre-defined bundles from tractograms, and bundles with high curvature such as the uncinate fasciculus and the fornix are challenging to extract. To mitigate this challenge, we mostly relied on algorithms that use priors to help generate fuller bundles. Still, to extract all bundles of interest, we needed to use multiple automated algorithms and perform rigorous visual inspection to make sure all algorithms yielded comparable bundles. The diffusion sequence relied on only one b-value, and future acquisitions with multiple b-values could further improve capturing fine-grained changes (Pines et al., 2020). Given the partial volume effect of PET, pathology at the cortical endpoints might be slightly affected with 
white matter uptake. To diminish this potential confound, we took advantage of the high 2-mm resolution of the scanner (HRRT) and did not smooth the SUVR images. This cohort is followed yearly on cognition and imaging, so future longitudinal studies will help clarify the potential biphasic relationship, as a proportion of participants will progress to mild cognitive impairment.

Overall, we used state-of-the-art analytical techniques to study associations between white matter microstructure and pathology in key bundles affected in $\mathrm{AD}$ in the PREVENT-AD cohort of cognitively normal older adults whose strong family history of AD suggests a two- to three-fold increased risk of subsequent dementia (Cupples et al., 2004; Devi et al., 2000). We suggest that our reliance on this cohort was important because $\mathrm{AD}$ pathology starts depositing in the asymptomatic phase of the disease, but extensive cortical pathology and atrophy are apparent by the time an individual develops cognitive impairment. PREVENT-AD and similar samples represent the sorts of groups that may be useful for clinical trials of preventive interventions (Meyer et al., 2019). As more studies highlight that white matter changes might precede changes in grey matter (Caso et al., 2016; Sachdev et al., 2013), studying the associations between pathology and microstructure in the early stages of AD will help understand better of the complex pathogenesis of the disease. 


\section{Materials and Methods}

\subsection{Participants}

We studied cognitively unimpaired participants at risk of sporadic AD dementia from the PRe-symptomatic EValuation of Experimental or Novel Treatments for AD (PREVENTAD) study. PREVENT-AD is a longitudinal study that started in 2012 (Breitner et al., 2016) and enrolled 386 participants. Inclusion criteria were as follows: (1) having intact cognition, (2) having a parent or two siblings diagnosed with AD-like dementia, and therefore being at increased risk of sporadic AD, (3) being above 60 years of age, or between 55 and 59 if fewer than 15 years from their affected family member's age at symptom onset, (4) being free of major neurological and psychiatric diseases. Intact cognition was based on the Montreal Cognitive Assessment, a Clinical Dementia Rating of 0 , and a standardized neuropsychological evaluation using the Repeatable Battery for the Assessment of Neuropsychological Status (Randolph et al., 1998). The cognitive status of individuals with questionable neuropsychological status was reviewed in consensus meetings of neuropsychologists (including SV) and/or psychiatrists. Annual visits include neuropsychological testing and a MRI session. Since 2017, A $\beta$ and tau PET scans were integrated to the study protocol for interested participants. The present study includes participants who had structural and diffusion-weighted MRI and who underwent PET, for a total of 126 participants. All participants included in the current study were cognitively normal at the time they underwent diffusion-weighted MRI.

\subsection{Image Acquisition}

\subsubsection{Magnetic resonance imaging}


T1-weighted structural and diffusion-weighted MRI were acquired on a Magnetom Tim Trio 3 Tesla (Siemens) scanner at the Douglas Mental Health University Institute prior to PET imaging. Structural scans were acquired yearly, and thus we selected the closest scan prior to PET (average time between PET and structural MRI: $8 \pm 4$ months). Diffusionweighted MRI was not acquired every year, and again the diffusion scan closest to PET was chosen for analysis (average time between PET and diffusion-weighted MRI: $1.1 \pm$ 0.8 years). Structural scans were acquired using a MPRAGE sequence with the following parameters: $\mathrm{TR}=2300 \mathrm{~ms} ; \mathrm{TE}=2.98 \mathrm{~ms} ; \mathrm{FA}=9^{\circ} ; \mathrm{FoV}=256 \mathrm{~mm}$; slice thickness $=1 \mathrm{~mm}$; 160-170 slices. Diffusion-weighted scans were acquired with the following parameters: $\mathrm{TR}=9300 \mathrm{~ms}$, TE: $92 \mathrm{~ms}, \mathrm{FoV}=130 \mathrm{~mm}$, slice thickness $=2 \mathrm{~mm}$. One b0 image was acquired and 64 diffusion-weighted volumes were acquired with a b-value of 1000 $\mathrm{s} / \mathrm{mm}^{2}$.

\subsubsection{Positron emission tomography}

PET was performed using $\left[{ }^{18} \mathrm{~F}\right] \mathrm{NAV} 4694$ to assess A $\beta$ burden and flortaucipir $\left(\left[{ }^{18} \mathrm{~F}\right] \mathrm{AV} 1451\right)$ to assess tau deposition. PET scanning took place at the McConnell Brain Imaging Centre at the Montreal Neurological Institute using a brain-dedicated PET Siemens/CT high-resolution research tomograph (HRRT) on two consecutive days. A $\beta$ scans were acquired 40 to 70 minutes post-injection $(\approx 6 \mathrm{mCi})$ and tau scans 80 to 100 minutes post-injection $(\approx 10 \mathrm{mCi})$. All scans were completed between March 2017 and April 2019. 


\subsection{Positron emission tomography processing}

PET scans were processed using a standard pipeline (see

https://github.com/villeneuvelab/vlpp for more details). Briefly, A $\beta$ - and tau-PET images

were realigned, averaged and registered to the T1-weighted scan of each participant, which had been segmented with the Desikan-Killiany atlas using FreeSurfer version 5.3 (Desikan et al., 2006). The same structural scan was used in the diffusion and the PET pipelines. PET images were then masked to remove the scalp and cerebrospinal fluid, to reduce contamination by non-grey and non-white matter voxels. Standardized uptake value ratios (SUVR) images were obtained using the whole cerebellum as reference region for A $\beta$-PET (Jagust et al., 2015) and the inferior cerebellar grey matter for tauPET (Baker et al., 2017). A global A $\beta$ burden was calculated from the average bilateral SUVR of medial and lateral frontal, parietal and temporal regions. A global score of temporal tau was calculated by taking the average bilateral SUVR from the entorhinal, amygdala, fusiform, inferior and middle temporal gyri (Ossenkoppele et al., 2018). However, the main interest was to extract $A \beta$ and tau SUVR at the cortical endpoints of the fibers forming each anatomical bundle of interest, and thus we registered the PET SUVR images to the diffusion image using ANTS (Avants et al., 2011). We also took advantage of the high 2-mm resolution of the PET-HRRT scanner and did not smooth the SUVR images. By doing so, we aimed to diminish mixing grey and white matter signal in each voxel, so that the SUVR values at the cortical endpoints of the fibers are more precise. 


\subsection{Diffusion MRI processing}

An overview of the processing steps is displayed in Figure 1.

\subsubsection{Preprocessing steps}

The diffusion-weighted images were processed using the TractoFlow Atlas-Based Segmentation (TractoFlow-ABS) pipeline. TractoFlow-ABS is an extension of the recent TractoFlow pipeline (Theaud et al., 2020a; Theaud et al., 2020b) publicly available for academic research purposes (https://github.com/scilus/tractoflow) that uses Nextflow (Di Tommaso et al., 2017) and Singularity (Kurtzer et al., 2017) to ensure efficient and reproducible diffusion processing. All major processing steps are performed through this pipeline, from preprocessing of the structural and diffusion images to tractography. The pipeline computes typical diffusion tensor imaging maps, fiber orientation distribution function (fODF) and a whole-brain tractogram. The pipeline calls different functions from various neuroimaging software, namely FSL (Jenkinson et al., 2012), MRtrix3 (Tournier et al., 2019), ANTs (Avants et al., 2011), and DIPY (Garyfallidis et al., 2014). For a detailed description of the different steps see (Theaud et al., 2020a).

\subsubsection{Diffusion measures}

After the preprocessing steps, different diffusion measures can be generated as part of TractoFlow or TractoFlow-ABS. The following diffusion tensor imaging (DTI) metrics were computed using DIPY: fractional anisotropy (FA), mean diffusivity (MD), radial diffusivity (RD) and axial diffusivity (AD). Along with typical DTI modeling, fiber orientation distribution functions (fODFs) were also computed using constrained spherical deconvolution (Descoteaux et al., 2007; Tournier et al., 2007) and the fiber response function from the group average. The fODF metric used in the current study was 
apparent fiber density along each bundle (AFD), which can be seen as an indirect measure of axonal density (Raffelt et al., 2012). AFD was calculated along each bundle in a fixel-based manner, reducing contamination from crossing fibers (Raffelt et al., 2015).

Along with the typical tensor metrics, we also generated free-water corrected DTI metrics, which were the main diffusion metrics of interest in this study. Free-water correction has been proposed has a way to remove the contamination of water from the tissue properties by modeling the isotropic diffusion of the free water component (Pasternak et al., 2009). Free-water modeling was performed using the accelerated microstructure imaging via convex optimization (Daducci et al., 2015) to calculate freewater index $(\mathrm{FW})$ and free-water corrected metrics, namely $\mathrm{FA}_{\mathrm{T}}, \mathrm{MD}_{\mathrm{T}}, \mathrm{AD}_{\mathrm{T}}$ and $\mathrm{RD}_{\mathrm{T}}$. Removing the contribution of free water is thought to better represent the tissue microstructure (hence the subscript ${ }_{\mathrm{T}}$ for tissue) and might be more sensitive than the non-corrected metrics (Albi et al., 2017; Chad et al., 2018; Pasternak et al., 2012).

\subsubsection{Tractography}

The last step of the pipeline is tractography. This is where Tractoflow and TractoflowABS differ. The former uses a more sophisticated algorithm, particle filtering tractography, that takes into account anatomical information to reduce tractography biases (Girard et al., 2014). Such an algorithm requires probabilistic maps of grey matter (GM), white matter (WM) and cerebrospinal fluid to add additional constraints for tracking. However, with aging, probabilistic maps in "bottleneck" areas of WM fibers, for example where the uncinate fasciculus bends, show poorer distinction between GM and WM voxels. Furthermore, increasing white matter hyperintensities and general 
atrophy with aging also complicate the use of more advanced algorithms. As a result, the performance particle filtering tractography was affected and failed to generate bundles suitable for analysis. Instead, as implemented in TractoFlow-ABS, we opted for local tracking with a probabilistic algorithm to reconstruct whole-brain tractograms. The inputs for tracking were the fODF image for directions and a WM mask for seeding. The mask was computed by joining the WM and the subcortical masks from the structural image that had been segmented with the Desikan-Killiany atlas in FreeSurfer version 5.3 (Desikan et al., 2006). For tracking, seeding was initiated in voxels from the WM mask with 10 seeds per voxel. The tractograms had between 2 and 3 million streamlines.

\subsection{White matter bundles extraction}

From the tractogram, we extracted different bundles of interest. We focussed on bundles connecting the main brain region where $\mathrm{A} \beta$ and tau accumulate in the early phase of $\mathrm{AD}$, namely the uncinate fasciculus, the cingulum, the posterior cingulum, and the fornix. To extract the uncinate fasciculus and the cingulum, we used RecoBundles X (Rheault, 2020), an automated algorithm to segment the tractograms into different bundles. This algorithm is an improved and more stable version of RecoBundles (Garyfallidis et al., 2018). Briefly, the method is based on shape priors to detect similarity in streamlines. Taking the whole-brain tractogram and templates from the bundles of interest as inputs, RecoBundles X extracts bundles based on the shape of the streamlines from the templates. The difference between RecoBundles and RecoBundles X resides in that the latter can take multiple templates as inputs and multiple parameters, which refines which streamlines are included or excluded from the final bundle. RecoBundles X is typically 
run 80 times and the output is the conjunction of the multiple runs, yielding more robust bundles. RecoBundles $\mathrm{X}$ does not include templates for the posterior cingulum or the fornix, and thus we used different methods to extract them. We used TractQuerier (Wassermann et al., 2016) to extract the posterior cingulum. This method works with customizable queries to extract bundles based on anatomical definitions. Using inclusion and exclusion regions of interest based on the FreeSurfer parcellation, we implemented a query specifically for the posterior cingulum. The query was also used in another recent study (Roy et al., 2020) and can be found in Supplementary material. The last bundle of interest was the fornix. The fornix is a difficult bundle to extract, given its high curvature, its proximity to cerebrospinal fluid increasing susceptibility to partial volume effects, and its location in regions prone to atrophy in aging and AD,. Therefore, we used a combination of different steps to generate this bundle. First, we ran Bundle-Specific Tractography (Rheault et al., 2019). This algorithm helps to increase the number of plausible streamlines, yielding a better spatial coverage and a more accurate representation of the full shape of the fornix. Bundle-Specific Tractography takes as input a template representing the fornix derived from 23 participants used in another study (Roy et al., 2020). This template, in the form of streamlines, generates spatial and orientational priors to enhance the fODF map and facilitate reconstruction of the fornix. Using Bundle-Specific Tractography to extract the fornix specifically is further detailed elsewhere (Rheault et al., 2018). Applied to cognitively normal older adults such as the PREVENT-AD participants, the algorithm yielded fornices with a very high number of streamlines and we implemented further steps to filter out the fornix tractograms: we excluded any streamlines going through the thalamus and through an eroded mask of 
CSF, and only retained streamlines going through the hippocampus. Finally, we removed the streamlines forming loops.

After extracting all bundles, each one was inspected visually in MI-Brain (https://www.imeka.ca/fr/mi-brain/) to make sure the shape, location and size were adequate. Only for the fornix did some participants have bundles that were too small. We excluded from analyses fornices containing less than 50 streamlines.

\subsection{Bundle-specific quantification with tractometry}

The last step required to put together the different white matter measures and bundles of interest was tractometry (Cousineau et al., 2017). Tractometry is a way to extract the measures of interest specifically in each bundle. It takes as input the maps of all microstructure measures and the bundles in which we want to extract them. In our case, we extracted the average bundle tissue measures $\left(\mathrm{FA}_{\mathrm{T}}, \mathrm{MD}_{\mathrm{T}}, \mathrm{RD}_{\mathrm{T}}, \mathrm{AD}_{\mathrm{T}}\right.$ and $\mathrm{FW}$ index $)$ and AFD as a fODF metric for each bundle (uncinate fasciculus, cingulum, posterior cingulum, fornix). For complementary analyses we also extracted typical tensor measures (average FA, MD, RD and AD) in each bundle. For the A $\beta$ and tau measurements, we extracted the average SUVR from the cortical endpoints of each bundle. By doing so, we have an average $A \beta /$ tau SUVR of all voxels specific to each bundle and participant. In the cingulum, the endpoints lie along the cingulate cortex. In the posterior cingulum, we extracted SUVR at both ends of the bundle, i.e. in the posterior cingulate and the medial temporal lobe. In the fornix, we extracted SUVR at the endpoints in the temporal lobe only. We did not consider the endpoints around the mammillary bodies, as they are 
regions with off-target binding in PET. In the uncinate fasciculus, we extracted SUVR at both ends of the bundle, i.e. in the frontal and temporal lobes. The overall approach, done entirely in native space, has the advantage of generating bundles specific to each individual and of capturing the amount of pathology specifically in the grey matter connected by such bundles.

\subsection{Statistical Analysis}

Linear regression models were performed to evaluate the relationships between $\mathrm{A} \beta$ or tau and the different microstructure measures in each bundle. In primary analyses, the diffusion measures investigated as independent variables were $F A_{T}, M D_{T}, R D_{T}, A D_{T}$, FW index and AFD. Regression models were performed separately for A $\beta$ and tau in the left and right bundles separately. Age, sex, and bundle volume (divided by total intracranial volume) were included as covariates in each regression model. We focused on the $A \beta$ and tau SUVR specifically at the endpoints of each bundle. In the bundles where associations were found between pathology and microstructure, we further adjusted for grey matter volume (divided by total intracranial volume) of cortical regions connected by the bundle to evaluate whether associations were also influenced by atrophy. For the uncinate fasciculus, GM regions of interest were medial orbitofrontal cortex and the parahippocampal gyrus; for the cingulum, regions were the anterior and posterior cingulate; for the posterior cingulum, regions were precuneus and parahippocampal gyrus; for the fornix, we used hippocampal volume. Lastly, when we found associations between different microstructure measures and one pathology (A $\beta$ or tau), we further corrected for the SUVR of the other protein at the same endpoints, to 
assess whether associations were specific to one protein. We also performed similar analyses with the typical tensor measures (FA, MD, AD and RD) to evaluate whether the free-water corrected metrics were more sensitive. As a last step, we evaluated associations between global A $\beta$ SUVR and tau meta-ROI SUVR and white matter microstructure. Associations with a p-value $<0.05$ were considered significant, but we also report associations that would survive false-discovery rate (FDR) correction for each bundle with q-value of 0.05 , accounting for 6 tests (i.e. the number of diffusion measures assessed per bundle). Analyses were conducted using SPSS version 20 (IBM, N.Y., USA) and R version 3.6.3 (Vienna, Austria) (2020).

\section{Acknowledgements}

The authors wish to acknowledge the staff of PREVENT-AD as well as of the Brain Imaging Centre of the Douglas Mental Health University Institute and of the PET unit of the McConnell Brain Imaging Centre of the Montreal Neurological Institute, and members of the SCIL lab. A full listing of members of the PREVENT-AD Research Group can be found at https://preventad.loris.ca/acknowledgements/acknowledgements.php?date=[2020-0630]. We would also like to acknowledge the participants of the PREVENT-AD cohort for dedicating their time and energy to helping us collect these data. Thank you to the Neuroinformatics Chair of the Université de Sherbrooke for supporting neuroscience research. 


\section{Competing interests}

Maxime Descoteaux is the co-founder of Imeka Solution Inc. No other author reports competing interests.

\section{References}

(2020). R: A language and environment for statistical computing. R Foundation for Statistical Computing. In R Core Team.

Agosta, F., Pievani, M., Sala, S., Geroldi, C., Galluzzi, S., Frisoni, G.B., and Filippi, M. (2011). White matter damage in Alzheimer disease and its relationship to gray matter atrophy. Radiology 258, 853-863.

Ahmed, Z., Cooper, J., Murray, T.K., Garn, K., McNaughton, E., Clarke, H., Parhizkar, S., Ward, M.A., Cavallini, A., Jackson, S., et al. (2014). A novel in vivo model of tau propagation with rapid and progressive neurofibrillary tangle pathology: the pattern of spread is determined by connectivity, not proximity. Acta Neuropathol 127, 667-683.

Albi, A., Pasternak, O., Minati, L., Marizzoni, M., Bartres-Faz, D., Bargallo, N., Bosch, B., Rossini, P.M., Marra, C., Muller, B., et al. (2017). Free water elimination improves test-retest reproducibility of diffusion tensor imaging indices in the brain: A longitudinal multisite study of healthy elderly subjects. Hum Brain Mapp 38, 12-26.

Alves, G.S., Oertel Knochel, V., Knochel, C., Carvalho, A.F., Pantel, J., Engelhardt, E., and Laks, J. (2015). Integrating retrogenesis theory to Alzheimer's disease pathology: insight from DTI-TBSS investigation of the white matter microstructural integrity. Biomed Res Int 2015, 291658.

Amlien, I.K., and Fjell, A.M. (2014). Diffusion tensor imaging of white matter degeneration in Alzheimer's disease and mild cognitive impairment. Neuroscience 276, 206-215.

Avants, B.B., Tustison, N.J., Song, G., Cook, P.A., Klein, A., and Gee, J.C. (2011). A reproducible evaluation of ANTs similarity metric performance in brain image registration. Neuroimage 54, 2033-2044.

Baker, S.L., Maass, A., and Jagust, W.J. (2017). Considerations and code for partial volume correcting [18F]-AV-1451 tau PET data. Data in Brief 15, 648-657.

Bartzokis, G. (2004). Age-related myelin breakdown: a developmental model of cognitive decline and Alzheimer's disease. Neurobiol Aging 25, 5-18; author reply 49-62. Bartzokis, G. (2011). Alzheimer's disease as homeostatic responses to age-related myelin breakdown. Neurobiol Aging 32, 1341-1371. 
Bateman, R.J., Xiong, C., Benzinger, T.L.S., Fagan, A.M., Goate, A., Fox, N.C., Marcus, D.S., Cairns, N.J., Xie, X., Blazey, T.M., et al. (2012). Clinical and Biomarker Changes in Dominantly Inherited Alzheimer's Disease. New England Journal of Medicine.

Berron, D., van Westen, D., Ossenkoppele, R., Strandberg, O., and Hansson, O. (2020). Medial temporal lobe connectivity and its associations with cognition in early Alzheimer's disease. Brain 143, 1233-1248.

Braak, H., and Braak, E. (1991). Neuropathological stageing of Alzheimer-related changes. Acta neuropathologica 82, 239-259.

Breitner, J.C.S., Poirier, J., Etienne, P.E., Leoutsakos, J.M., and Group, P.-A.D.R. (2016). Rationale and Structure for a New Center for Studies on Prevention of Alzheimer's Disease (StoP-AD). Journal of Prevention of Alzheimer's Disease 3, 236-242.

Bubb, E.J., Metzler-Baddeley, C., and Aggleton, J.P. (2018). The cingulum bundle: Anatomy, function, and dysfunction. Neurosci Biobehav Rev 92, 104-127.

Buckner, R.L., Snyder, A.Z., Shannon, B.J., Larossa, G., Sachs, R., Fotenos, A.F., Sheline, Y.I., Klunk, W.E., Mathis, C.A., Morris, J.C., et al. (2005). Molecular, Structural, and Functional Characterization of Alzheimer's Disease : Evidence for a Relationship between Default Activity, Amyloid, and Memory. Journal of Neuroscience 25, 7709-7717.

Caso, F., Agosta, F., and Filippi, M. (2016). Insights into White Matter Damage in Alzheimer's Disease: From Postmortem to in vivo Diffusion Tensor MRI Studies. Neurodegener Dis 16, 26-33.

Chad, J.A., Pasternak, O., Salat, D.H., and Chen, J.J. (2018). Re-examining age-related differences in white matter microstructure with free-water corrected diffusion tensor imaging. Neurobiol Aging 71, 161-170.

Cousineau, M., Jodoin, P.M., Morency, F.C., Rozanski, V., Grand'Maison, M., Bedell, B.J., and Descoteaux, M. (2017). A test-retest study on Parkinson's PPMI dataset yields statistically significant white matter fascicles. Neuroimage Clin 16, 222-233.

Cupples, L.A., Farrer, L.A., Sadovnick, A.D., and Relkin, N. (2004). Estimating risk curves for first-degree relatives of patients with Alzheimer' $s$ disease : The REVEAL study. Genetics in Medicine 6, 192-196.

Daducci, A., Canales-Rodriguez, E.J., Zhang, H., Dyrby, T.B., Alexander, D.C., and Thiran, J.P. (2015). Accelerated Microstructure Imaging via Convex Optimization (AMICO) from diffusion MRI data. Neuroimage 105, 32-44.

Descoteaux, M., Angelino, E., Fitzgibbons, S., and Deriche, R. (2007). Regularized, fast, and robust analytical Q-ball imaging. Magn Reson Med 58, 497-510. 
Desikan, R.S., Ségonne, F., and Fischl, B. (2006). An automated labeling system for subdividing the human cerebral cortex on MRI scans into gyral based regions of interest. Neuroimage 31, 968-980.

Devi, G., Ottman, R., Tang, M.X., Marder, K., Stern, Y., and Mayeux, R. (2000). Familial aggregation of Alzheimer disease among whites, African Americans, and Caribbean Hispanics in northern Manhattan. Arch Neurol 57, 72-77.

Di Tommaso, P., Chatzou, M., Floden, E.W., Barja, P.P., Palumbo, E., and Notredame, C. (2017). Nextflow enables reproducible computational workflows. Nat Biotechnol 35, 316-319.

Dong, J.W., Jelescu, I.O., Ades-Aron, B., Novikov, D.S., Friedman, K., Babb, J.S., Osorio, R.S., Galvin, J.E., Shepherd, T.M., and Fieremans, E. (2020). Diffusion MRI biomarkers of white matter microstructure vary nonmonotonically with increasing cerebral amyloid deposition. Neurobiol Aging 89, 118-128.

Duyckaerts, C., Delatour, B., and Potier, M.C. (2009). Classification and basic pathology of Alzheimer disease. Acta Neuropathol 118, 5-36.

Dyrby, T.B., Lundell, H., Burke, M.W., Reislev, N.L., Paulson, O.B., Ptito, M., and Siebner, H.R. (2014). Interpolation of diffusion weighted imaging datasets. Neuroimage 103, 202-213.

Fjell, A.M., McEvoy, L., Holland, D., Dale, A.M., Walhovd, K.B., and Alzheimer's Disease Neuroimaging, I. (2014). What is normal in normal aging? Effects of aging, amyloid and Alzheimer's disease on the cerebral cortex and the hippocampus. Prog Neurobiol 117, 20-40.

Fortea, J., Sala-Llonch, R., Bartres-Faz, D., Bosch, B., Llado, A., Bargallo, N., Molinuevo, J.L., and Sanchez-Valle, R. (2010). Increased cortical thickness and caudate volume precede atrophy in PSEN1 mutation carriers. J Alzheimers Dis 22, 909-922.

Franzmeier, N., Neitzel, J., Rubinski, A., Smith, R., Strandberg, O., Ossenkoppele, R., Hansson, O., Ewers, M., and Alzheimer's Disease Neuroimaging, I. (2020). Functional brain architecture is associated with the rate of tau accumulation in Alzheimer's disease. Nat Commun 11, 347.

Franzmeier, N., Rubinski, A., Neitzel, J., Kim, Y., Damm, A., Na, D.L., Kim, H.J., Lyoo, C.H., Cho, H., Finsterwalder, S., et al. (2019). Functional connectivity associated with tau levels in ageing, Alzheimer's, and small vessel disease. Brain 142, 1093-1107.

Garyfallidis, E., Brett, M., Amirbekian, B., Rokem, A., van der Walt, S., Descoteaux, M., Nimmo-Smith, I., and Dipy, C. (2014). Dipy, a library for the analysis of diffusion MRI data. Front Neuroinform 8,8 . 
Garyfallidis, E., Cote, M.A., Rheault, F., Sidhu, J., Hau, J., Petit, L., Fortin, D., Cunanne, S., and Descoteaux, M. (2018). Recognition of white matter bundles using local and global streamline-based registration and clustering. Neuroimage 170, 283-295.

Girard, G., Whittingstall, K., Deriche, R., and Descoteaux, M. (2014). Towards quantitative connectivity analysis: reducing tractography biases. Neuroimage 98, 266278.

Harrison, J.R., Bhatia, S., Tan, Z.X., Mirza-Davies, A., Benkert, H., Tax, C.M.W., and Jones, D.K. (2020). Imaging Alzheimer's genetic risk using diffusion MRI: A systematic review. Neuroimage Clin 27, 102359.

Higuchi, M., Lee, V.M., and Trojanowski, J.Q. (2002). Tau and axonopathy in neurodegenerative disorders. Neuromolecular Med 2, 131-150.

Iqbal, K., Liu, F., Gong, C.X., Alonso Adel, C., and Grundke-Iqbal, I. (2009).

Mechanisms of tau-induced neurodegeneration. Acta Neuropathol 118, 53-69.

Jack, C.R., Knopman, D.S., Jagust, W.J., Petersen, R.C., Weiner, M.W., Aisen, P.S., Shaw, L.M., Vemuri, P., Wiste, H.J., Weigand, S.D., et al. (2013). Tracking pathophysiological processes in Alzheimer's disease: An updated hypothetical model of dynamic biomarkers. The Lancet Neurology 12, 207-216.

Jacobs, H.I.L., Hedden, T., Schultz, A.P., Sepulcre, J., Perea, R.D., Amariglio, R.E., Papp, K.V., Rentz, D.M., Sperling, R.A., and Johnson, K.A. (2018). Structural tract alterations predict downstream tau accumulation in amyloid-positive older individuals. Nat Neurosci 21, 424-431.

Jagust, W.J., Landau, S.M., Koeppe, R.A., Reiman, E.M., Chen, K., Mathis, C.A., Price, J.C., Foster, N.L., and Wang, A.Y. (2015). The Alzheimer's Disease Neuroimaging Initiative 2 PET Core: 2015. Alzheimers Dement 11, 757-771.

Jansen, W.J., Ossenkoppele, R., Knol, D.L., Tijms, B.M., Scheltens, P., Verhey, F.R.J., Visser, P.J., Aalten, P., Aarsland, D., Alcolea, D., et al. (2015). Prevalence of Cerebral Amyloid Pathology in Persons Without Dementia: A Meta-analysis. Jama 313, 19241938.

Jenkinson, M., Beckmann, C.F., Behrens, T.E., Woolrich, M.W., and Smith, S.M. (2012). FSL. NeuroImage 62, 782-790.

Johnson, K.A., Schultz, A., Betensky, R.A., Becker, J.A., Sepulcre, J., Rentz, D., Mormino, E., Chhatwal, J., Amariglio, R., Papp, K., et al. (2016). Tau positron emission tomographic imaging in aging and early Alzheimer disease. Ann Neurol 79, 110-119. 
Jones, D.T., Graff-Radford, J., Lowe, V.J., Wiste, H.J., Gunter, J.L., Senjem, M.L., Botha, H., Kantarci, K., Boeve, B.F., Knopman, D.S., et al. (2017). Tau, amyloid, and cascading network failure across the Alzheimer's disease spectrum. Cortex 97, 143-159.

Kantarci, K., Murray, M.E., Schwarz, C.G., Reid, R.I., Przybelski, S.A., Lesnick, T., Zuk, S.M., Raman, M.R., Senjem, M.L., Gunter, J.L., et al. (2017). White-matter integrity on DTI and the pathologic staging of Alzheimer's disease. Neurobiol Aging 56, 172-179.

Klunk, W.E., Engler, H., Nordberg, A., Wang, Y., Blomqvist, G., Holt, D.P., Bergström, M., Savitcheva, I., Huang, G.F., Estrada, S., et al. (2004). Imaging Brain Amyloid in Alzheimer's Disease with Pittsburgh Compound-B. Annals of Neurology 55, 306-319.

Kurtzer, G.M., Sochat, V., and Bauer, M.W. (2017). Singularity: Scientific containers for mobility of compute. PLoS One 12, e0177459.

Mattsson, N., Palmqvist, S., Stomrud, E., Vogel, J., and Hansson, O. (2019). Staging beta-Amyloid Pathology With Amyloid Positron Emission Tomography. JAMA Neurol.

McSweeney, M., Pichet Binette, A., Meyer, P.F., Gonneaud, J., Bedetti, C., Ozlen, H., Labonte, A., Rosa-Neto, P., Breitner, J., Poirier, J., et al. (2020). Intermediate flortaucipir uptake is associated with Abeta-PET and CSF tau in asymptomatic adults. Neurology 94, e1190-e1200.

Meyer, P.F., Tremblay-Mercier, J., Leoutsakos, J., Madjar, C., Lafaille-Maignan, M.E., Savard, M., Rosa-Neto, P., Poirier, J., Etienne, P., Breitner, J., et al. (2019). INTREPAD: A randomized trial of naproxen to slow progress of presymptomatic Alzheimer disease. Neurology 92, e2070-e2080.

Mito, R., Raffelt, D., Dhollander, T., Vaughan, D.N., Tournier, J.D., Salvado, O., Brodtmann, A., Rowe, C.C., Villemagne, V.L., and Connelly, A. (2018). Fibre-specific white matter reductions in Alzheimer's disease and mild cognitive impairment. Brain 141, 888-902.

Montal, V., Vilaplana, E., Alcolea, D., Pegueroles, J., Pasternak, O., Gonzalez-Ortiz, S., Clarimon, J., Carmona-Iragui, M., Illan-Gala, I., Morenas-Rodriguez, E., et al. (2018). Cortical microstructural changes along the Alzheimer's disease continuum. Alzheimers Dement $14,340-351$.

Mormino, E.C., Smiljic, A., Hayenga, A.O., Onami, S.H., Greicius, M.D., Rabinovici, G.D., Janabi, M., Baker, S.L., Yen, I.V., Madison, C.M., et al. (2011). Relationships between $\beta$-amyloid and functional connectivity in different components of the default mode network in aging. Cerebral cortex (New York, NY : 1991) 21, 2399-2407.

Oishi, K., and Lyketsos, C.G. (2014). Alzheimer's disease and the fornix. Front Aging Neurosci 6, 241. 
Ossenkoppele, R., Rabinovici, G.D., Smith, R., Cho, H., Scholl, M., Strandberg, O., Palmqvist, S., Mattsson, N., Janelidze, S., Santillo, A., et al. (2018). Discriminative Accuracy of [18F]flortaucipir Positron Emission Tomography for Alzheimer Disease vs Other Neurodegenerative Disorders. JAMA 320, 1151-1162.

Palop, J.J., and Mucke, L. (2010). Amyloid-beta-induced neuronal dysfunction in Alzheimer's disease: from synapses toward neural networks. Nat Neurosci 13, 812-818.

Pasternak, O., Sochen, N., Gur, Y., Intrator, N., and Assaf, Y. (2009). Free water elimination and mapping from diffusion MRI. Magn Reson Med 62, 717-730.

Pasternak, O., Westin, C.F., Bouix, S., Seidman, L.J., Goldstein, J.M., Woo, T.U., Petryshen, T.L., Mesholam-Gately, R.I., McCarley, R.W., Kikinis, R., et al. (2012). Excessive extracellular volume reveals a neurodegenerative pattern in schizophrenia onset. J Neurosci 32, 17365-17372.

Pereira, J.B., Ossenkoppele, R., Palmqvist, S., Strandberg, T.O., Smith, R., Westman, E., and Hansson, O. (2019). Amyloid and tau accumulate across distinct spatial networks and are differentially associated with brain connectivity. Elife 8 .

Pichet Binette, A., Gonneaud, J., Vogel, J.W., La Joie, R., Rosa-Neto, P., Collins, D.L., Poirier, J., Breitner, J.C.S., Villeneuve, S., Vachon-Presseau, E., et al. (2020). Morphometric network differences in ageing versus Alzheimer's disease dementia. Brain $143,635-649$.

Pines, A.R., Cieslak, M., Larsen, B., Baum, G.L., Cook, P.A., Adebimpe, A., Davila, D.G., Elliott, M.A., Jirsaraie, R., Murtha, K., et al. (2020). Leveraging multi-shell diffusion for studies of brain development in youth and young adulthood. Dev Cogn Neurosci 43, 100788.

Racine, A.M., Adluru, N., Alexander, A.L., Christian, B.T., Okonkwo, O.C., Oh, J., Cleary, C.A., Birdsill, A., Hillmer, A.T., Murali, D., et al. (2014). Associations between white matter microstructure and amyloid burden in preclinical Alzheimer's disease: A multimodal imaging investigation. Neuroimage Clin 4, 604-614.

Raffelt, D., Tournier, J.D., Rose, S., Ridgway, G.R., Henderson, R., Crozier, S., Salvado, O., and Connelly, A. (2012). Apparent Fibre Density: a novel measure for the analysis of diffusion-weighted magnetic resonance images. Neuroimage 59, 3976-3994.

Raffelt, D.A., Smith, R.E., Ridgway, G.R., Tournier, J.D., Vaughan, D.N., Rose, S., Henderson, R., and Connelly, A. (2015). Connectivity-based fixel enhancement: Wholebrain statistical analysis of diffusion MRI measures in the presence of crossing fibres. Neuroimage 117, 40-55. 
Randolph, C., Tierney, M.C., Mohr, E., and Chase, T.N. (1998). The Repeatable Battery for the Assessment of Neuropsychological Status (RBANS): Preliminary Clinical Validity. Journal of Clinical and Experimental Neuropsychology 20, 310-319.

Rheault, F. (2020). Analyse et reconstruction de faisceaux de la matière blanche. In Computer Science (Université de Sherbrooke), pp. 258.

Rheault, F., Houde, J.C., and Descoteaux, M. (2017). Visualization, Interaction and Tractometry: Dealing with Millions of Streamlines from Diffusion MRI Tractography. Front Neuroinform 11, 42.

Rheault, F., Poulin, P., Valcourt Caron, A., St-Onge, E., and Descoteaux, M. (2020). Common misconceptions, hidden biases and modern challenges of dMRI tractography. J Neural Eng 17, 011001.

Rheault, F., Roy, M., Cunnane, S., and Descoteaux, M. (2018). Bundle-specific fornix reconstruction for dual-tracer PET-tractometry. BioRxiv preprint, 12.

Rheault, F., St-Onge, E., Sidhu, J., Maier-Hein, K., Tzourio-Mazoyer, N., Petit, L., and Descoteaux, M. (2019). Bundle-specific tractography with incorporated anatomical and orientational priors. Neuroimage 186, 382-398.

Rieckmann, A., Van Dijk, K.R., Sperling, R.A., Johnson, K.A., Buckner, R.L., and Hedden, T. (2016). Accelerated decline in white matter integrity in clinically normal individuals at risk for Alzheimer's disease. Neurobiol Aging 42, 177-188.

Roy, M., Rheault, F., Croteau, E., Castellano, C.A., Fortier, M., St-Pierre, V., Houde, J.C., Turcotte, E.E., Bocti, C., Fulop, T., et al. (2020). Fascicle- and Glucose-Specific Deterioration in White Matter Energy Supply in Alzheimer's Disease. J Alzheimers Dis.

Sachdev, P.S., Zhuang, L., Braidy, N., and Wen, W. (2013). Is Alzheimer's a disease of the white matter? Curr Opin Psychiatry 26, 244-251.

Schöll, M., Lockhart, S.N., Schonhaut, D.R., O'Neil, J.P., Janabi, M., Ossenkoppele, R., Baker, S.L., Vogel, J.W., Faria, J., Schwimmer, H.D., et al. (2016). PET Imaging of Tau Deposition in the Aging Human Brain. Neuron 89, 971-982.

Seeley, W.W., Crawford, R.K., Zhou, J., Miller, B.L., and Michael, D. (2009).

Neurodegenerative diseases target large-scale human brain networks. Neuron 62, 42-52.

Sepulcre, J., Sabuncu, M.R., Li, Q., El Fakhri, G., Sperling, R., and Johnson, K.A. (2017). Tau and amyloid-?? proteins distinctively associate to functional network changes in the aging brain. Alzheimer's and Dementia, 1-9. 
Sepulcre, J., Schultz, A.P., Sabuncu, M., Gomez-Isla, T., Chhatwal, J., Becker, A., Sperling, R., and Johnson, K.A. (2016). In Vivo Tau, Amyloid, and Gray Matter Profiles in the Aging Brain. J Neurosci 36, 7364-7374.

Sexton, C.E., Kalu, U.G., Filippini, N., Mackay, C.E., and Ebmeier, K.P. (2011). A metaanalysis of diffusion tensor imaging in mild cognitive impairment and Alzheimer's disease. Neurobiol Aging 32, 2322 e2325-2318.

Song, Z., Farrell, M.E., Chen, X., and Park, D.C. (2018). Longitudinal accrual of neocortical amyloid burden is associated with microstructural changes of the fornix in cognitively normal adults. Neurobiol Aging 68, 114-122.

Sperling, R.A., Aisen, P.S., Beckett, L.A., Bennett, D.A., Craft, S., Fagan, A.M., Iwatsubo, T., Jack, C.R., Kaye, J., Montine, T.J., et al. (2011). Toward defining the preclinical stages of Alzheimer's disease: Recommendations from the National Institute on Aging-Alzheimer's Association workgroups on diagnostic guidelines for Alzheimer's disease, pp. 280-292.

Spires-Jones, T.L., and Hyman, B.T. (2014). The intersection of amyloid beta and tau at synapses in Alzheimer's disease. Neuron 82, 756-771.

Strain, J.F., Smith, R.X., Beaumont, H., Roe, C.M., Gordon, B.A., Mishra, S., Adeyemo, B., Christensen, J.J., Su, Y., Morris, J.C., et al. (2018). Loss of white matter integrity reflects tau accumulation in Alzheimer disease defined regions. Neurology 91, e313e318.

Theaud, G., Houde, J.-C., Boré, A., Rheault, F., Morency, F., and Descoteaux, M. (2020a). TractoFlow: A robust, efficient and reproducible diffusion MRIpipeline leveraging Nextflow \& Singularity. BioRxiv preprint.

Theaud, G., Houde, J.C., Bore, A., Rheault, F., Morency, F., and Descoteaux, M. (2020b). TractoFlow: A robust, efficient and reproducible diffusion MRI pipeline leveraging Nextflow \& Singularity. Neuroimage 218, 116889.

Tournier, J.D., Calamante, F., and Connelly, A. (2007). Robust determination of the fibre orientation distribution in diffusion MRI: non-negativity constrained super-resolved spherical deconvolution. Neuroimage 35, 1459-1472.

Tournier, J.D., Smith, R., Raffelt, D., Tabbara, R., Dhollander, T., Pietsch, M., Christiaens, D., Jeurissen, B., Yeh, C.H., and Connelly, A. (2019). MRtrix3: A fast, flexible and open software framework for medical image processing and visualisation. Neuroimage 202, 116137.

van der Kant, R., Goldstein, L.S.B., and Ossenkoppele, R. (2020). Amyloid-betaindependent regulators of tau pathology in Alzheimer disease. Nat Rev Neurosci 21, 21 35 . 
Villeneuve, S., Rabinovici, G.D., Cohn-Sheehy, B.I., Madison, C., Ayakta, N., Ghosh, P.M., La Joie, R., Arthur-Bentil, S.K., Vogel, J.W., Marks, S.M., et al. (2015). Existing Pittsburgh Compound-B positron emission tomography thresholds are too high: statistical and pathological evaluation. Brain : a journal of neurology 138, 2020-2033.

Vipin, A., Ng, K.K., Ji, F., Shim, H.Y., Lim, J.K.W., Pasternak, O., Zhou, J.H., and Alzheimer's Disease Neuroimaging, I. (2019). Amyloid burden accelerates white matter degradation in cognitively normal elderly individuals. Hum Brain Mapp 40, 2065-2075.

Vogel, J.W., Iturria-Medina, Y., Strandberg, O.T., Smith, R., Levitis, E., Evans, A.C., Hansson, O., Alzheimer's Disease Neuroimaging, I., and Swedish BioFinder, S. (2020). Spread of pathological tau proteins through communicating neurons in human Alzheimer's disease. Nat Commun 11, 2612.

Von Der Heide, R.J., Skipper, L.M., Klobusicky, E., and Olson, I.R. (2013). Dissecting the uncinate fasciculus: disorders, controversies and a hypothesis. Brain 136, 1692-1707. Wang, Q., Wang, Y., Liu, J., Sutphen, C.L., Cruchaga, C., Blazey, T., Gordon, B.A., Su, Y., Chen, C., Shimony, J.S., et al. (2019). Quantification of white matter cellularity and damage in preclinical and early symptomatic Alzheimer's disease. Neuroimage Clin 22, 101767.

Wassermann, D., Makris, N., Rathi, Y., Shenton, M., Kikinis, R., Kubicki, M., and Westin, C.F. (2016). The white matter query language: a novel approach for describing human white matter anatomy. Brain Struct Funct 221, 4705-4721.

Wen, Q., Mustafi, S.M., Li, J., Risacher, S.L., Tallman, E., Brown, S.A., West, J.D., Harezlak, J., Farlow, M.R., Unverzagt, F.W., et al. (2019). White matter alterations in early-stage Alzheimer's disease: A tract-specific study. Alzheimers Dement (Amst) 11, 576-587.

Zhang, X., Sun, Y., Li, W., Liu, B., Wu, W., Zhao, H., Liu, R., Zhang, Y., Yin, Z., Yu, T., et al. (2019). Characterization of white matter changes along fibers by automated fiber quantification in the early stages of Alzheimer's disease. Neuroimage Clin 22, 101723.

Zhuang, L., Sachdev, P.S., Trollor, J.N., Kochan, N.A., Reppermund, S., Brodaty, H., and Wen, W. (2012). Microstructural white matter changes in cognitively normal individuals at risk of amnestic MCI. Neurology 79, 748-754. 


\section{Supplementary material}

TractQuerier query to extract the posterior cingulum

Supplementary Figure 1. No associations between diffusion measures and tau in the cingulum and fornix

Supplementary Figure 2. No associations between diffusion measures and pathology in the posterior cingulum

Supplementary Table 1. Associations between diffusion measures and pathology in the uncinate fasciculus when adjusting for the other pathology

Supplementary Table 2. Associations between typical tensor measures and pathology in the uncinate fasciculus 


\title{
TractQuerier query to extract the posterior cingulum
}

\author{
import FreeSurfer.qry \\ \#Posterior cingulum \\ Posterior_Cg.side = only(isthmuscingulate. side or \\ posteriorcingulate.side and (entorhinal.side or fusiform.side or \\ parahippocampal.side or precuneus.side or lingual.side or \\ amygdala. side))
}




\section{Supplementary Figure 1. No associations between diffusion measures and tau in the cingulum and fornix}

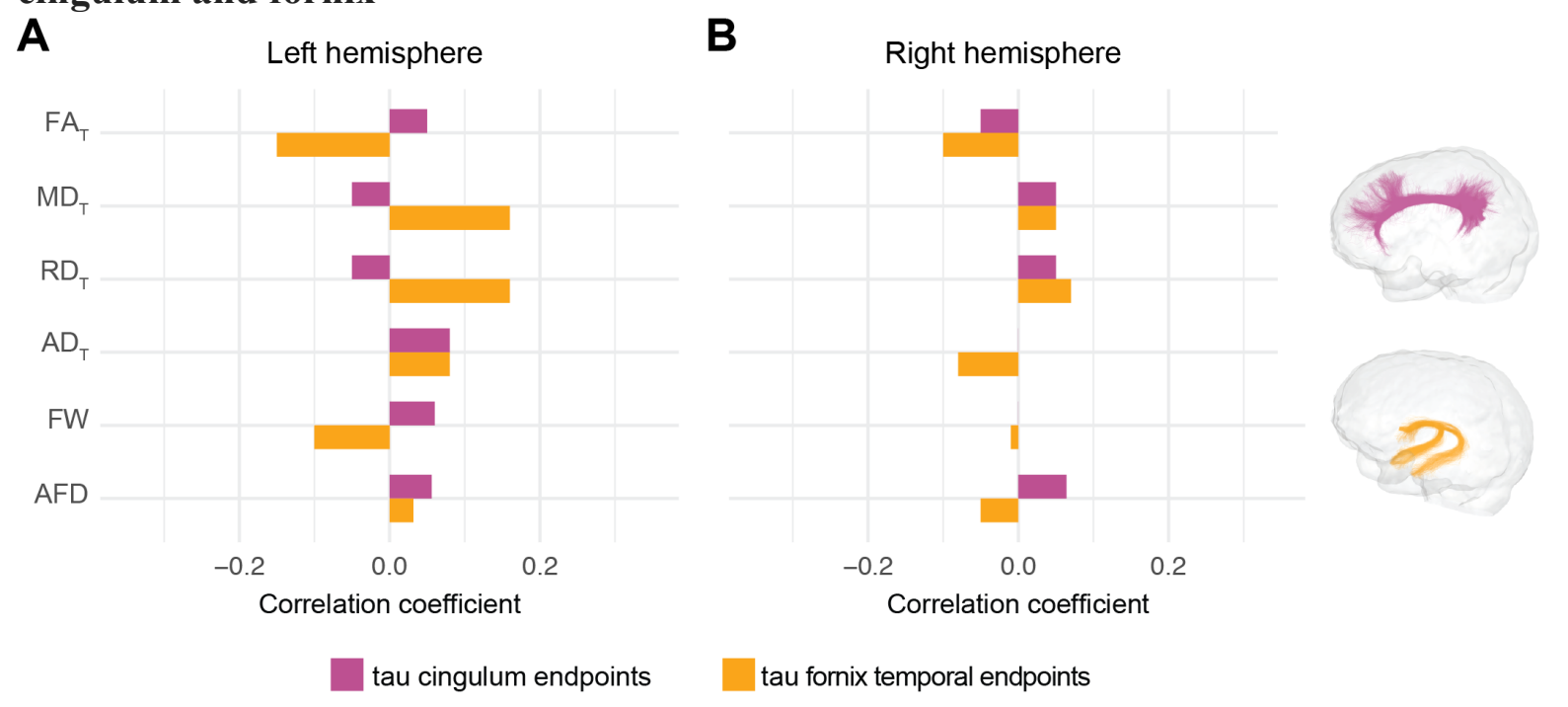

$\mathrm{R}_{\text {partial }}$ from regression models investigating associations between each diffusion metric (average diffusion measure in the bundle; independent variable) and tau pathology at the cortical endpoints of the bundle in the left (A) and right (B) hemispheres. Magenta bars correspond to associations in the cingulum and orange bars, in the fornix. Models included age, sex, bundle volume (divided by total intracranial volume) as covariates.

$\mathrm{A} \beta$ : beta-amyloid; $\mathrm{FA}_{\mathrm{T}}$ : tissue fractional anisotropy; $\mathrm{MD}_{\mathrm{T}}$ : tissue mean diffusivity; $\mathrm{AD}_{\mathrm{T}}$ : tissue axial diffusivity; $\mathrm{RD}_{\mathrm{T}}$ : tissue radial diffusivity; FW: free-water index; AFD: fixel-based apparent fiber density 


\section{Supplementary Figure 2. No associations between diffusion measures and pathology in the posterior cingulum}

A

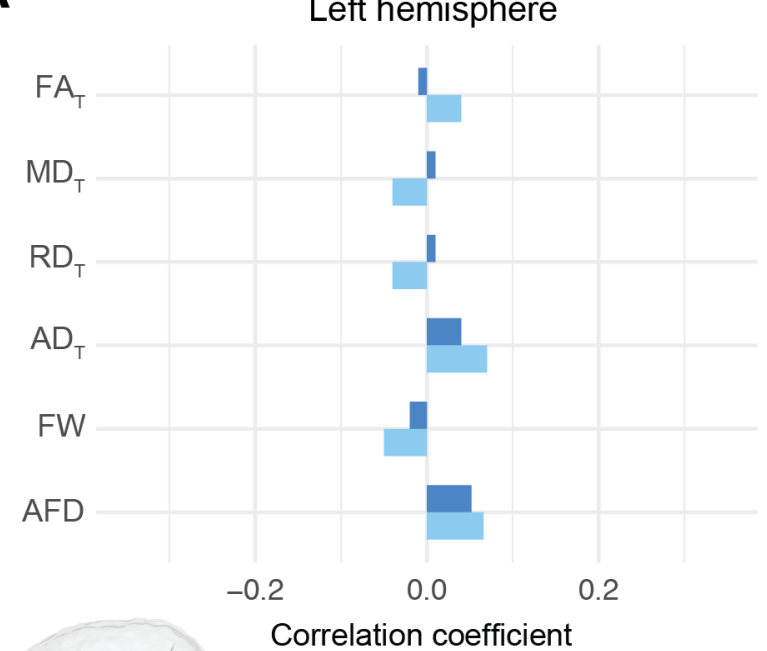

$A \beta$ head endpoints

C

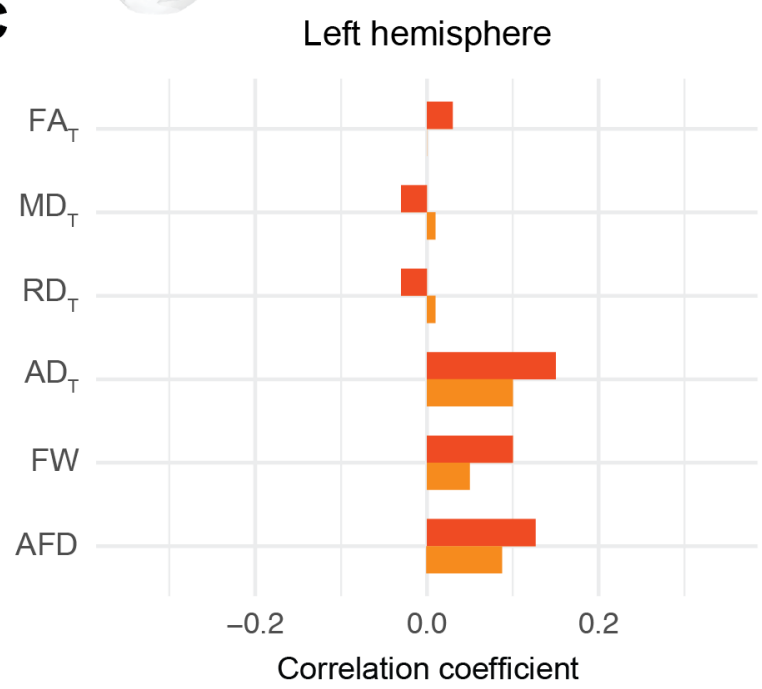

tau head endpoints
B

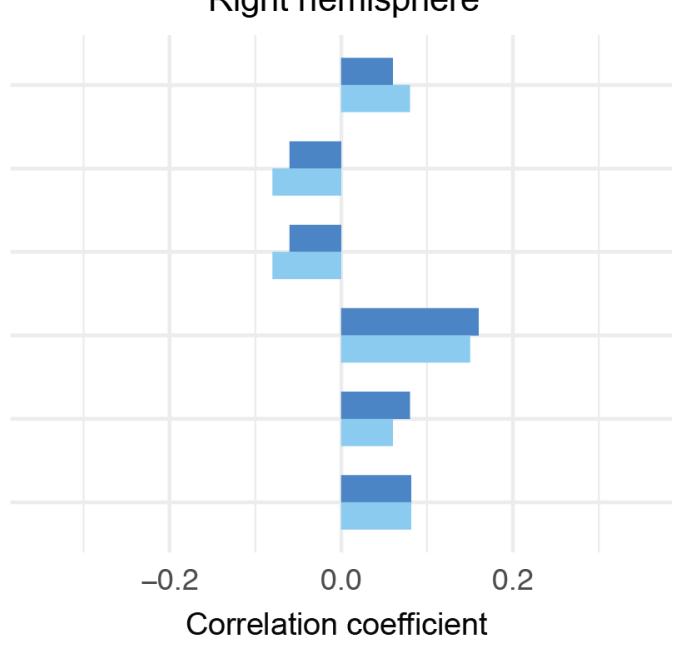

$A \beta$ tail endpoints

Dight hemisphere

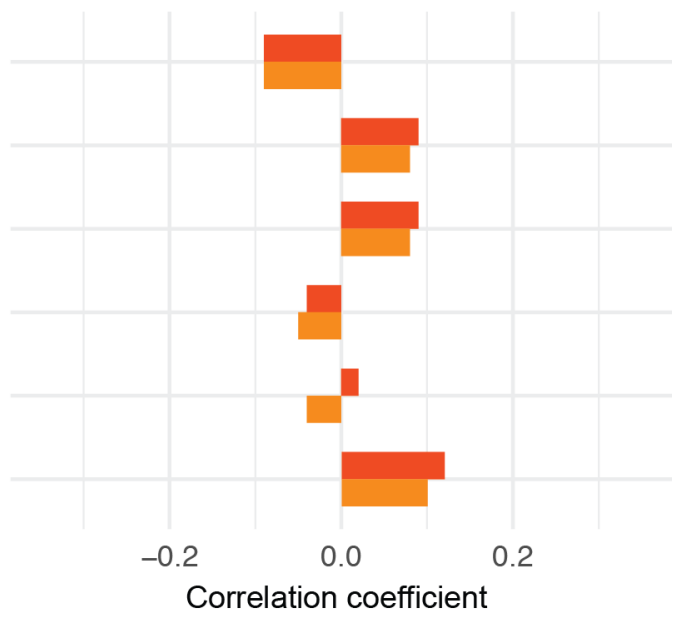

tau tail endpoints

$\mathrm{R}_{\text {partial }}$ from regression models investigating associations between each diffusion metric (average diffusion measure in the bundle; independent variable) and $A \beta(A-B)$ or tau $(C-D)$ pathology at the cortical endpoints of the two ends of the posterior cingulum in the left hemisphere and right hemispheres. Models included age, sex, bundle volume (divided by total intracranial volume) as covariates.

$\mathrm{A} \beta$ : beta-amyloid; $\mathrm{FA}_{\mathrm{T}}$ : tissue fractional anisotropy; $\mathrm{MD}_{\mathrm{T}}$ : tissue mean diffusivity; $\mathrm{AD}_{\mathrm{T}}$ : tissue axial diffusivity; $\mathrm{RD}_{\mathrm{T}}$ : tissue radial diffusivity; FW: free-water index; AFD: fixel-based apparent fiber density 
Supplementary Table 1. Associations between diffusion measures and pathology in the uncinate fasciculus when adjusting for the other pathology

\begin{tabular}{|c|c|c|c|c|c|c|c|c|c|c|c|c|}
\hline$n=126$ & \multicolumn{6}{|c|}{ Left hemisphere } & \multicolumn{6}{|c|}{ Right hemisphere } \\
\hline \multicolumn{13}{|c|}{ Associations with $\mathbf{A \beta}$} \\
\hline & $\mathbf{F} \mathbf{A}_{\mathrm{T}}$ & $\mathbf{M D}_{\mathrm{T}}$ & $\mathbf{A} \mathbf{D}_{\mathrm{T}}$ & $\mathbf{R D}_{\mathrm{T}}$ & FW & AFD & $\mathbf{F A}_{\mathbf{T}}$ & $\mathbf{M D}_{\mathrm{T}}$ & $\mathbf{A D}_{\mathrm{T}}$ & $\mathbf{R D}_{\mathrm{T}}$ & FW & AFD \\
\hline $\begin{array}{l}\text { Frontal } \\
\text { endpoints }\end{array}$ & $\begin{array}{l}0.16 \\
(0.08)\end{array}$ & $\begin{array}{l}-0.17 \\
(0.07)\end{array}$ & $\begin{array}{l}0.07 \\
(0.43)\end{array}$ & $\begin{array}{l}-0.16 \\
(0.07)\end{array}$ & $\begin{array}{l}-0.08 \\
(0.36)\end{array}$ & $\begin{array}{l}0.14 \\
(0.14)\end{array}$ & $\begin{array}{l}0.13 \\
(0.17)\end{array}$ & $\begin{array}{l}-0.13 \\
(0.17)\end{array}$ & $\begin{array}{l}0.13 \\
(0.17)\end{array}$ & $\begin{array}{l}-0.13 \\
(0.17)\end{array}$ & $\begin{array}{l}0.06 \\
(0.49)\end{array}$ & $\begin{array}{l}0.05 \\
(0.57)\end{array}$ \\
\hline $\begin{array}{l}\text { Temporal } \\
\text { endpoints }\end{array}$ & $\begin{array}{l}0.16 \\
(0.08)\end{array}$ & $\begin{array}{l}-0.16 \\
(0.08)\end{array}$ & $\begin{array}{l}0.08 \\
(0.38)\end{array}$ & $\begin{array}{l}-0.16 \\
(0.08)\end{array}$ & $\begin{array}{l}0.01 \\
(0.96)\end{array}$ & $\begin{array}{l}0.11 \\
(0.24)\end{array}$ & $\begin{array}{l}0.11 \\
(0.24)\end{array}$ & $\begin{array}{l}-0.11 \\
(0.24)\end{array}$ & $\begin{array}{l}0.09 \\
(0.31)\end{array}$ & $\begin{array}{c}-0.11 \\
(0.24)\end{array}$ & $\begin{array}{l}0.14 \\
(0.12)\end{array}$ & $\begin{array}{l}0.00 \\
(0.95)\end{array}$ \\
\hline \multicolumn{13}{|c|}{ Associations with tau } \\
\hline $\begin{array}{l}\text { Frontal } \\
\text { endpoints }\end{array}$ & $\begin{array}{l}0.26 \\
(0.00 \\
4)\end{array}$ & $\begin{array}{l}-0.26 \\
(0.00 \\
4)\end{array}$ & $\begin{array}{l}0.20 \\
(0.03)\end{array}$ & $\begin{array}{l}-0.26 \\
(0.00 \\
4)\end{array}$ & $\begin{array}{l}-0.03 \\
(0.74)\end{array}$ & $\begin{array}{l}0.19 \\
(0.04)\end{array}$ & $\begin{array}{l}0.23 \\
(0.01)\end{array}$ & $\begin{array}{l}-0.23 \\
(0.01)\end{array}$ & $\begin{array}{l}0.19 \\
(0.03)\end{array}$ & $\begin{array}{l}-0.23 \\
(0.01)\end{array}$ & $\begin{array}{l}0.23 \\
(0.01)\end{array}$ & $\begin{array}{l}0.14 \\
(0.14)\end{array}$ \\
\hline $\begin{array}{l}\text { Temporal } \\
\text { endpoints }\end{array}$ & $\begin{array}{l}0.16 \\
(0.08)\end{array}$ & $\begin{array}{l}-0.16 \\
(0.08)\end{array}$ & $\begin{array}{l}0.14 \\
(0.14)\end{array}$ & $\begin{array}{l}-0.16 \\
(0.08)\end{array}$ & $\begin{array}{l}0.05 \\
(0.57)\end{array}$ & $\begin{array}{l}0.08 \\
(0.41)\end{array}$ & $\begin{array}{l}0.19 \\
(0.04)\end{array}$ & $\begin{array}{l}-0.19 \\
(0.04)\end{array}$ & $\begin{array}{l}0.17 \\
(0.07)\end{array}$ & $\begin{array}{l}-0.19 \\
(0.04)\end{array}$ & $\begin{array}{l}0.27 \\
(0.00 \\
3)\end{array}$ & $\begin{array}{l}0.06 \\
(0.55)\end{array}$ \\
\hline
\end{tabular}

$\mathrm{R}_{\text {partial }}$ and ( $\mathrm{p}$-values) from regression models investigating associations between each diffusion metric (average diffusion measure in the bundle; independent variable) and pathology at the cortical endpoints of the two ends of the uncinate facsciculus (dependent variable). Models included age, sex, uncinate fasciculus volume (divided by total intracranial volume), and the amount of the other pathology at the corresponding endpoints as covariates. For example, in a model with $A \beta$ at the frontal endpoints as the dependent variable, tau at the same endpoints is a covariate.

$\mathrm{A} \beta$ : beta-amyloid; $\mathrm{FA}_{\mathrm{T}}$ : tissue fractional anisotropy; $\mathrm{MD}_{\mathrm{T}}$ : tissue mean diffusivity; $\mathrm{AD}_{\mathrm{T}}$ : tissue axial diffusivity; $\mathrm{RD}_{\mathrm{T}}$ : tissue radial diffusivity; FW: free-water index; $\mathrm{AFD}$ : fixel-based apparent fiber density

Supplementary Table 2. Associations between typical tensor measures and pathology in the uncinate fasciculus

\begin{tabular}{|c|c|c|c|c|c|c|c|c|}
\hline$n=126$ & \multicolumn{4}{|c|}{ Left hemisphere } & \multicolumn{4}{|c|}{ Right hemisphere } \\
\hline \multicolumn{9}{|c|}{ Associations with $\mathbf{A} \beta$} \\
\hline & FA & MD & AD & RD & FA & MD & AD & RD \\
\hline $\begin{array}{l}\text { Frontal } \\
\text { endpoints }\end{array}$ & $\begin{array}{l}0.22 \\
(0.02)\end{array}$ & $\begin{array}{l}-0.13 \\
(0.16)\end{array}$ & $\begin{array}{l}0.15 \\
(0.11)\end{array}$ & $\begin{array}{l}-0.20 \\
(0.03)\end{array}$ & $\begin{array}{l}0.07 \\
(0.46)\end{array}$ & $\begin{array}{l}-0.01 \\
(0.96)\end{array}$ & $\begin{array}{l}0.06 \\
(0.53)\end{array}$ & $\begin{array}{l}-0.04 \\
(0.69)\end{array}$ \\
\hline $\begin{array}{l}\text { Temporal } \\
\text { endpoints }\end{array}$ & $\begin{array}{l}0.14 \\
(0.12)\end{array}$ & $\begin{array}{l}-0.05 \\
(0.63)\end{array}$ & $\begin{array}{l}0.14 \\
(0.12)\end{array}$ & $\begin{array}{l}-0.11 \\
(0.22)\end{array}$ & $\begin{array}{l}0.01 \\
(0.88)\end{array}$ & $\begin{array}{l}0.06 \\
(0.55)\end{array}$ & $\begin{array}{l}0.08 \\
(0.38)\end{array}$ & $\begin{array}{l}0.03 \\
(0.73)\end{array}$ \\
\hline \multicolumn{9}{|c|}{ Associations with tau } \\
\hline $\begin{array}{l}\text { Frontal } \\
\text { endpoints }\end{array}$ & $\begin{array}{l}0.28 \\
(0.002)\end{array}$ & $\begin{array}{l}-0.14 \\
(0.13)\end{array}$ & $\begin{array}{l}0.20 \\
(0.03)\end{array}$ & $\begin{array}{l}-0.24 \\
(0.01)\end{array}$ & $\begin{array}{l}0.12 \\
(0.18)\end{array}$ & $\begin{array}{l}0.09 \\
(0.32)\end{array}$ & $\begin{array}{l}0.24 \\
(0.009)\end{array}$ & $\begin{array}{l}0.00 \\
(0.98)\end{array}$ \\
\hline $\begin{array}{l}\text { Temporal } \\
\text { endpoints }\end{array}$ & $\begin{array}{l}0.15 \\
(0.11)\end{array}$ & $\begin{array}{l}-0.02 \\
(0.85)\end{array}$ & $\begin{array}{l}0.16 \\
(0.08)\end{array}$ & $\begin{array}{l}-0.09 \\
(0.33)\end{array}$ & $\begin{array}{l}0.05 \\
(0.60)\end{array}$ & $\begin{array}{l}0.17 \\
(0.07)\end{array}$ & $\begin{array}{l}0.27 \\
(0.003)\end{array}$ & $\begin{array}{l}0.08 \\
(0.38)\end{array}$ \\
\hline
\end{tabular}

$\mathrm{R}_{\mathrm{partial}}$ and (p-values) from regression models investigating associations between each tensor metric (average diffusion measure in the bundle; independent variable) and pathology at the cortical endpoints of the two ends of the uncinate facsciculus (dependent variable). Models included age, sex, bundle volume (divided by total intracranial volume) as covariates.

$\mathrm{A} \beta$ : beta-amyloid; FA: fractional anisotropy; MD: mean diffusivity; AD: axial diffusivity; RD: radial diffusivity 